\title{
A Rational Explanation For Home Country Bias
}

By

\author{
Iftekhar Hasan \\ New York University \\ 44 West $4^{\text {th }}$ Street \\ New York, NY 10023 \\ Phone: (212) 998-0329 \\ ihasan@stern.nyu.edu \\ Yusif Simaan \\ Graduate School of Management \\ Fordham University at Lincoln Center \\ 113 West $60^{\text {th }}$ Street \\ New York, New York 10023 \\ 2126780757 \\ simaan@ibm.net
}

Accepted for publications in

Journal of International Money and Finance

The authors would like to thank Chris Blake, Tom Berglund, Sris Chatterjee, Larry Gorman, Jim Lothian, Harry Markowitz, Andy Naranjo Steve Smith, Kenneth West, and David Whitcomb. Natural caveats apply. 


\title{
A Rational Explanation For Home Country Bias
}

\begin{abstract}
While modern portfolio theory predicts that investors should diversify across international markets, corporate equity is essentially held by domestic investors. French and Poterba (1991) suggest that in order for this bias to be justified, investors must hold optimistic expectations about their domestic markets and pessimistic expectations about their foreign markets. Tesar and Werner (1995) find existing explanations to the home equity bias unsatisfactory and conclude that the issue poses a challenge for portfolio theory. We develop a model that incorporates both the foregone gains from diversification and the informational constraints of international investing, and shows that home equity bias is consistent with rational mean-variance portfolio choice. Specifically, we prove that the nature of estimation risk in international markets can be responsible for this phenomenon. We show that when the cross-market variability in the estimation errors of international markets' means far exceeds the cross-market variability in the means themselves, domestic dedication dominates international diversification. An examination of eleven international markets' returns over the last twenty-five years, from the perspective of German, Japanese and U.S investors provides evidence consistent with this explanation.
\end{abstract}




\section{A Rational Explanation For Home Country Bias}

\section{Introduction}

Applying the seminal portfolio selection framework of Markowitz (1952), Levy and Sarnat (1970) shows that the correlation structure of international equity markets contains great advantage for portfolio diversification. Later work by Solnik (1974b), Solnik and Noetzlin (1982), Grauer and Hakansson (1987), Levy and Lerman (1988) and Odier and Solnik (1993) confirms this premise. However, French and Poterba (1991) investigate international ownership patterns and demonstrate that corporate equity is held by domestic investors and that little cross-border diversification takes place either in the U.S or Japan. They show that current portfolio holdings can be justified if investors hold optimistic expectations about their home market and pessimistic expectation about their foreign markets. In addition, they point out that investors have higher unwarranted risk perceptions about foreign assets due to relative unfamiliarity with foreign markets and institutions.

Mussa and Goldstein (1993) take the home bias phenomenon as evidence that international capital markets are far from integrated. While they conclude that what accounts for the home country bias remains a puzzle, they express their preference for the explanation of French and Poterba (1991). Cooper and Kaplanis (1994) conclude that home bias cannot be explained by either inflation hedging or direct observable costs of international investment. Kang and Stulz (1996) confirm the existence of substantial home bias and show that ownership of foreign investors in the Japanese market is biased against small stocks. They show that portfolio selection models that incorporate different forms of deadweight costs can explain home bias. However, such models fail to explain the bias of foreign investors against small stocks. Griffin (1997) reports that the typical pension and insurance portfolio appears to be sub-optimal due to a high concentration of domestic securities and that measuring portfolio risk relative to liabilities still validates the presence of strong home country bias.

Tesar and Werner (1995) examine the long-term investment patterns of five major OECD countries by using a larger data set than that of French and Poterba (1991). Their findings confirm the evidence of the home country bias. They show that international investment positions are well below the current limitations on foreign holdings of institutional investors. In addition they report a high turnover rate on foreign equity investments relative to the turnover in domestic equity markets. These observations rule out institutional constraints and transaction costs on foreign investing as potential 
explanations for the home country bias. Tesar and Werner (1995) conjecture that the explanation for the home bias requires a richer model for portfolio analysis, one that incorporates the foregone gains of international diversification and other informational and institutional constraints.

We develop a model that incorporates both of the previous perspectives. It provides a rational explanation for the home bias and posits investment behavior that is consistent with expected utility maximization and capital market equilibrium. The portfolio model assumes [Markowitz (1952)] that the investor has full information with regard to the mean vector and the covariance matrix of asset returns in the investment universe. The benefits of international diversification, cited above, are based on taking the sample estimators of both the mean vector and the covariance matrix to replace their true values in the optimization process. However, the estimators are subject to estimation errors that make any diversified portfolio based on these estimators sub-optimal relative to the full information optimal portfolios. Since investors have to estimate the parameters of the asset returns' probability distribution, the full information optimal portfolios are not feasible. The investor is left to make a choice between the sub-optimal diversified portfolios based on false values of the true parameters or the sub-optimal home country dedicated portfolio. Indeed, the fact that the true distribution parameters have to be estimated poses severe informational constraints on the model.

This paper examines the conditions under which rational investors facing estimation errors prefer domestic dedication over international diversification. Then it shows that the current pattern of under-diversification can be attributed to the nature of the estimation risk in international investing. We follow the assumptions of French and Poterba (1991) regarding investors' preferences and asset returns distribution. ${ }^{1}$ However, we assume that investors do not know the joint distribution parameters but instead estimate them using sample data. We show that estimation errors in both the mean vector and the covariance matrix induce biases in portfolio allocations and thus result in inefficient portfolio choices. Recent papers by Dumas and Solnik (1995), as well as Harvey (1991) and Ferson and Harvey (1993), test versions of the international CAPM with explicit treatment of estimation risk. However, they focus upon "market segmentation" and do not address home bias.

\footnotetext{
${ }^{1}$ Following French and Porteba (1991), we do not make any assumption regarding the purchasing power parity and moreover like most studies in portfolio analysis, we do not assume a risk free asset.
} 
Simaan (1993) defines the "opportunity cost" of a sub-optimal portfolio as the premium for an invested dollar that the investor is willing to pay to exchange his suboptimal portfolio with the optimal one. Simaan (1997) extends this concept to determine the opportunity of estimation risk as the premium on an invested dollar that the investor is willing to pay to avoid estimation risk. Following Simaan $(1993,1997)$ we derive the premium on an invested dollar that the investor is willing to pay to buy the full information of the mean vector. We show that such a premium is increasing in two factors: (i) the investor's risk tolerance and (ii) the cross-country variability of the errors in estimating the mean returns of international equity markets. Next we compare this premium to the premium that the investor is willing to pay to exchange a portfolio dedicated to the home country with the optimal one. Then we show that variability in the estimation errors that far exceeds the variability in the means can induce rational investors to prefer homecountry dedicated portfolios over diversified portfolios.

To investigate the nature of estimation risk in international investing we use monthly returns on equity markets in 11 countries over the period 1974-1994. We evaluate the effectiveness of international diversification to investors in Germany, Japan and the U.S over the period 1980-1994. We show that only a subset of investors on the higher end of risk aversion prefers international diversification in the three countries. On average, U.S. investors who tolerate a standard deviation of $3.92 \%$ per month or higher prefer not to diversify. For Germany and Japan these thresholds are 5.78\% and $6.25 \%$ accordingly. These thresholds of the three countries are lower than the standard deviations of their respective markets. If the markets' standard deviations reflect the risk tolerance of their representative investors, then the above thresholds indicate that representative investors in the three countries exhibit home country bias. We compare the opportunity cost of the estimation error to that of the opportunity cost of foregoing international diversification for three levels of relative risk aversion. We show that the opportunity cost of diversification for investors, who should not diversify, far exceeds the opportunity cost of foregoing diversification for investors who should diversify.

We investigate whether restrictions on short sales can enhance the zone of advantage of international diversification. The presence of short sales constraints does not allow the derivation of closed-form terms for the optimal portfolios, their estimators, or the opportunity cost of the estimators. Nevertheless, we can calculate these values numerically irrespective of investors' knowledge on the covariance matrix. We find that restricting the investor only to long positions in international equity markets and limiting his allocation to less than $50 \%$ in any single foreign market expand the zone of advantage of international diversification. The opportunity cost shows a slight decline for risk-averse 
investors and a very significant decline for aggressive investors, regardless of the home country. This makes international diversification superior to domestic dedication. However, the marginal advantage in the U.S is approximately $0.2 \%$ on an invested dollar for all levels of risk aversion. Such an advantage is less than the transaction costs associated with international investing, at least to a large group of investors. ${ }^{2}$ The marginal advantage for aggressive German and Japanese investors is also approximately $0.2 \%$. However, such marginal advantage is $0.6 \%$ for moderately risk averse investors in Germany and Japan while it exceeds $1 \%$ for risk averse investors.

The first section develops the model that incorporates estimation risk and the foregone gain from diversification and contrasts diversification decisions under estimation risk versus home dedication. The second section provides empirical investigation of the issue in two settings: The first assumes a stationary return distribution and examines estimation errors in the mean vector and the covariance matrix. The second investigates the sensitivity of the results to the stationarity assumption by allowing the means to change over time and their estimators to depend on conditional information observable at time portfolio allocations are made. In addition, we explore the ability of the investor to reduce the opportunity cost of estimation errors using self-imposed short sales constraints.

\section{Portfolio Allocation and Estimation Risk}

In this section, we develop a model that incorporates estimation risk and the foregone gain from diversification. Let $\tilde{\mathbf{R}}=\left(\mathrm{r}_{1}, \ldots, \mathrm{r}_{\mathrm{d}}\right)^{\prime}$ be the return (unity plus the rate of return) vector on $d$ international equity markets, and let $\mathbf{e}=(1, \ldots, 1)^{`}$. A portfolio is a vector $\mathbf{X}=\left(\mathrm{x}_{1}, \ldots, \mathrm{x}_{\mathrm{d}}\right)^{\prime}$ such that $\mathrm{X}^{\prime} \mathbf{e}=1$. The return on the portfolio is $\tilde{r_{p}}=\mathbf{X}^{\prime} \tilde{\mathbf{R}}$. Assume that the investor's current wealth is $w_{o}$ and his terminal wealth is $\tilde{w}=w_{0} \tilde{r_{p}}$. Following French and Poterba (1991) we assume that (i) asset returns follow a joint normal distribution with a mean $\mu$ and a covariance matrix $\Sigma$, and (ii) the representative investor in each country has a Constant Absolute Risk Aversion (CARA) utility of wealth given as $\mathrm{U}(\tilde{\mathrm{w}})=-\exp \{-\mathrm{a} \tilde{\mathrm{w}}\}$. If we let $\mathrm{A}=\mathrm{aw}_{\mathrm{o}}$, then the utility can be written as $\mathrm{U}(\tilde{\mathrm{w}})$ $\left.=-\exp \left\{-\tilde{A r}_{\mathrm{p}}\right)\right\}$ where $\mathrm{A}$ is the measure of relative risk aversion. The expected utility is given as: ${ }^{3}$

\footnotetext{
${ }^{2}$ Mussa and Goldstein (1993) point to a host of transaction costs to cross-border investments extending from differences in language and information to official restrictions and policies that favor domestic asset trade. However, there is no easily interpreted measure of the economic importance of these transaction costs.

${ }^{3}$ While French and Poterba (1991) state explicitly assumption (ii), assumption (i) is not mentioned. However, they use equation (1) as an implication of assumption (ii). But under
} 
$\mathrm{u}=\mathrm{E}\{\mathrm{U}(\tilde{\mathrm{w}})\}=-\exp \left\{-\mathrm{A} \mathbf{X}^{\prime} \boldsymbol{\mu}+(1 / 2) \mathrm{A}^{2} \mathbf{X}^{\prime} \boldsymbol{\Sigma} \mathbf{X}\right\}$

Let $\mathrm{h}=-\ln (-\mathrm{u})=\mathrm{A} \mathbf{X}^{\prime} \boldsymbol{\mu}-(1 / 2) \mathrm{A}^{2} \mathbf{X}^{\prime} \Sigma \mathbf{X}$. Since $\mathrm{h}$ is an increasing function of $\mathrm{u}$, maximizing $\mathrm{u}$ is equivalent to maximizing $\mathrm{h}$. Therfore, the optimal portfolio solves the following problem:

maximize $\quad \mathrm{h}=\mathrm{A} \mathbf{X}^{\prime} \boldsymbol{\mu}-(1 / 2) \mathrm{A}^{2} \mathbf{X}^{\prime} \Sigma \mathbf{X}$

subject to $\mathbf{X}^{\prime} \mathbf{e}=1$.

Let $\mathrm{L}=\mathrm{h}+\lambda\left(1-\mathbf{X}^{\prime} \mathbf{e}\right)$. The first order condition is:

$(\partial \mathrm{L} / \partial \mathbf{X})=\mathrm{A} \boldsymbol{\mu}-(1 / 2) \mathrm{A}^{2} \Sigma \mathbf{X}-\lambda \mathbf{e}=\mathbf{0}$

implying

$$
\mathbf{X}=\Sigma^{-1} \mu-\lambda \Sigma^{-1} \mathbf{e}
$$

Multiplying the above equation by $\mathbf{e}^{\prime}$, letting $\mu_{\mathrm{o}}=\mu^{\prime} \Sigma^{-1} \mathbf{e} / \mathbf{e}^{\prime} \Sigma^{-1} \mathbf{e}$, solving for $\lambda$, and denoting the optimal portfolio by $\mathbf{X}^{*}$, we arrive at

$$
\begin{aligned}
\mathbf{X}^{*} & =\Sigma^{-1} \mathbf{e} / \mathbf{e}^{\prime} \Sigma^{-1} \mathbf{e}+(1 / \mathrm{A}) \Sigma^{-1} \mathbf{e}\left[\boldsymbol{\mu}-\left(\boldsymbol{\mu}^{\prime} \Sigma^{-1} \mathbf{e} / \mathbf{e}^{\prime} \Sigma^{-1} \mathbf{e}\right) \mathbf{e}\right] \\
& =\alpha_{0}+(1 / \mathrm{A}) \Sigma^{-1}\left[\boldsymbol{\mu}-\mu_{\mathrm{o}} \mathbf{e}\right]
\end{aligned}
$$

Here $\alpha_{0}$ is the global minimum variance portfolio and $\mu_{\mathrm{o}}$ is its mean. Since $\Sigma$ is positive definite, the portfolio in (2) maximizes $h$. When $A \rightarrow \propto$, the optimal portfolio is the global minimum variance portfolio, $\alpha_{0}$.

\subsection{Estimation errors:}

(ii), equation (1) takes place if and only if the portfolio return is normally distributed. This is because assumption (i) implies that $\tilde{r_{p}} \sim N\left(\mu_{p}, \sigma_{p}^{2}\right)$, with a moment generating function $\Phi_{r}(\mathrm{t})=\mathrm{E}\{\exp (\tilde{\operatorname{rap}})\}=\exp \left\{\mu_{\mathrm{p}} \mathrm{t}+(1 / 2) \mathrm{t}^{2} \sigma^{2} \mathrm{p}\right\}$. Assumption (ii) implies that $\mathrm{u}=$ $\Phi_{r}(-\mathrm{A})=-\exp \left\{-\mathrm{A} \mu_{\mathrm{p}}+(1 / 2) \mathrm{A}^{2} \sigma^{2} \mathrm{p}\right\}=\exp \left\{-\mathrm{A} \mathbf{X}^{\prime} \boldsymbol{\mu}+(1 / 2) \mathrm{A}^{2} \mathbf{X}^{\prime} \Sigma \mathbf{X}\right\}$. Since the moment generating function uniquely determines the distribution of $\tilde{\mathrm{rp}_{\mathrm{p}}}$, equation (1) implies the normality of $\tilde{\mathrm{rp}_{\mathrm{p}}}$. 
Since the investor knows neither $\mu$ nor $\Sigma$, the portfolio in equation (2) is not feasible. We investigate the implication of estimation errors on the portfolio allocation, in two stages: First we assume that the investor knows the covariance matrix $\Sigma$, but estimates the mean vector $\boldsymbol{\mu}$ by $\mathbf{m}$. Second, we assume that the investor estimates the covariance matrix $\Sigma$ by $\mathbf{S}$. We assume that both $\Sigma$ and $\mathbf{S}$ are non-singular.

\section{$\underline{\sum \text { is Known: }}$}

Using $\mathbf{m}$ instead of $\boldsymbol{\mu}$ in equation (2), the investor estimates $\mathbf{X}^{*}$ by

$$
\hat{\mathbf{X}}=\boldsymbol{\alpha}_{0}+(1 / \mathrm{A}) \boldsymbol{\Sigma}^{-1}\left[\mathbf{m}-\mathbf{m}^{\prime} \boldsymbol{\alpha}_{0} \mathbf{e}\right]
$$

If we let the estimation error vector be $\mathbf{b}=\mathbf{m}-\boldsymbol{\mu}$, then substituting $\mathbf{m}=\boldsymbol{\mu}+\mathbf{b}$ in

and using (2) implies,

$$
\hat{\mathbf{X}}=\mathbf{X}^{*}+\Sigma^{-1}\left[\mathbf{b}-\mathbf{b}_{0} \mathbf{e}\right]
$$

where $b_{o}=b^{\prime} \Sigma^{-1} \mathbf{e} / \mathbf{e}^{\prime} \Sigma^{-1} \mathbf{e}$ is the bias of the global minimum variance portfolio mean. Of course, as long as the biases in estimating the means are not identical acröss national markets, $\mathbf{X}$ is sub-optimal. ${ }^{4}$ Let the mean of the optimal portfolio be $\mu_{\mathrm{p}}={ }_{\wedge} \boldsymbol{\mu} \mathbf{X}^{*}$, the optimal variance be $\sigma_{p}^{2}=\mathbf{X}^{*} \cdot \Sigma^{-1} \mathbf{X}^{*}$, the mean of the estimated portfolio $\mu_{\mathrm{p}}=\boldsymbol{\mu}^{\prime} \mathbf{X}$ and the variance of the estimated portfolio $\hat{\sigma}_{p}^{2}=\hat{X} \cdot \Sigma \hat{X}$. Multiplying (4) from the left by $\mu$ ' yields:

$$
\hat{\mu_{p}}=\hat{\mathbf{X}} \boldsymbol{\mu}=\hat{\mu}_{\mathrm{p}}+(1 / \mathrm{A}) \boldsymbol{\mu}^{\prime} \Sigma^{-1}\left[\mathbf{b}-\mathrm{b}_{\mathrm{o}} \mathbf{e}\right] .
$$

By definiton,

$$
\hat{\sigma}_{p}^{2}=\hat{\mathbf{X}} \boldsymbol{\Sigma} \hat{\mathbf{X}}=\hat{\sigma}_{\mathrm{p}}^{*}+\left(2 / \mathrm{A}^{2}\right) \boldsymbol{\mu}^{\prime} \Sigma^{-1}\left[\mathbf{b}-\mathrm{b}_{0} \mathbf{e}\right]+\left(1 / \mathrm{A}^{2}\right)\left[\mathbf{b}-\mathrm{b}_{0} \mathbf{e}\right]^{\prime} \Sigma^{-1}\left[\mathbf{b}-\mathrm{b}_{0} \mathbf{e}\right] .
$$

The second terms on the right hand sides of equation (4), (5.a) and (6.b) give the respective biases in the portfolio weights vector, the portfolio mean and the portfolio variance resulting from the estimation errors in the mean vector.

4. ${ }^{4}$ Recall that $b_{0}$ is a weighted average of the $b_{i}$. The weight of asset $i$ is equal to the $\mathrm{i}^{\text {th }}$

entry of the global minimum variance portfolio, $\alpha_{0}$. If $b_{i}=b$ then $b=b e$, and $\mathrm{b}_{0}=\alpha_{0}{ }^{\prime} \mathbf{e b}=\mathrm{b}$. Thus $\mathbf{b}-\mathbf{b}_{0} \mathbf{e}=\mathbf{0}$ and $\hat{\mathbf{X}}=\mathbf{X}^{*}$. 


\section{$\underline{\Sigma}$ is not Known:}

If we replace $\boldsymbol{\mu}$ and $\Sigma$ by $\mathbf{m}$ and $\mathbf{S}$ in equation (2) and let $\mathbf{a}_{0}=\mathbf{S}^{-1} \mathbf{e} / \mathbf{e}^{\mathbf{e}} \mathbf{S}^{-1} \mathbf{e}$ be the estimator of the GMV portfolio $\boldsymbol{\alpha}_{0}$ then the optimal portfolio based on $\mathbf{m}$ and $\mathbf{S}$ is:

$$
\hat{X}=\mathbf{a}_{0}+(1 / A) \mathbf{S}^{-1}\left[\mathbf{m}-\mathbf{m}^{\prime} \mathbf{a}_{0} \mathbf{e}\right] .
$$

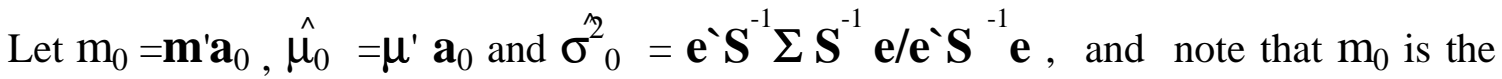
estimated mean of the GMV portfolio estimator, $\mathbf{a}_{0}$, where as $\hat{\mu_{0}}$ is its true mean. Similarly, $\sigma_{0}^{2}$ is the true variance of $\mathbf{a}_{0}$. With this notation, the mean-variance pair of the optimal portfolio based on $\mathbf{m}$ and $\mathbf{S}$ are :

$$
\begin{gathered}
\hat{\mu_{p}}=\hat{\mathbf{X}} \cdot \boldsymbol{\mu}=\hat{\mu}_{0}+(1 / \mathrm{A}) \boldsymbol{\mu}^{\prime} \mathbf{S}^{-1}\left[\mathbf{m}-\mathrm{m}_{0} \mathbf{e}\right] \\
\hat{\sigma_{\mathrm{p}}^{2}}=\hat{\mathbf{X}} \Sigma \hat{\mathbf{X}}=\hat{\sigma}_{0}^{2}+(2 / \mathrm{A}) \mathbf{a}_{0}{ }^{\prime} \Sigma \mathbf{S}^{-1}\left[\mathbf{m}-\mathrm{m}_{0} \mathbf{e}\right]+\left(1 / \mathrm{A}^{2}\right)\left[\mathbf{m}-\mathrm{m}_{0} \mathbf{e}\right] \mathbf{S}^{-1} \Sigma \mathbf{S}^{-1}\left[\mathbf{m}-\mathrm{m}_{0} \mathbf{e}\right]
\end{gathered}
$$

\subsection{The opportunity cost of the estimation error:}

We define the opportunity cost of the estimation error as the maximum price on an invested dollar that the investor is willing to pay to purchase the true mean. Suppose that the investor is willing to pay $\theta \mathrm{w}_{\mathrm{o}}$ in order to buy information on $\mu$. The investment return net of the information cost is $\left[\mathrm{w}_{0} \mathbf{X} \smile \tilde{\mathbf{R}}-\theta \mathrm{w}_{0}\right]$. Its expected utility is $\mathrm{E}\left\{\mathrm{U}\left(\operatorname{wo}_{\Lambda}[\mathbf{X} \smile \tilde{\mathbf{R}}-\theta]\right)\right\}$. If the investor does not buy $\boldsymbol{\mu}$, he invests in $\mathbf{X}$ with expected utility $\mathrm{E}\left\{\mathrm{U}\left(\mathrm{w}_{0} \mathbf{X} \smile \tilde{\mathbf{R}}\right)\right\}$. Hence the maximum amount per invested dollar that the investor is willing to pay for acquiring $\mu$, is the value of $\theta$ that solves the following equation:

$$
\mathrm{E}\left\{\mathrm{U}\left(\mathrm{w}_{0} \hat{\mathbf{X}} \cdot \tilde{\mathbf{R}}\right)\right\}=\mathrm{E}\left\{\mathrm{U}\left(\mathrm{w}_{0}[\mathbf{X} ` \tilde{\mathbf{R}}-\theta]\right)\right\} .
$$

Essentially $\theta$ is the opportunity cost of the sub-optimal portfolio, $\hat{\mathbf{X}}$. This definition of $\theta$ is given in Simaan (1993) in a different context and under a different name. It was called the optimization premium and was used to measure the opportunity cost of the mean-variance investment strategy as a second best to the expected utility maximization strategy when the former is sub-optimal. West, Edison and Cho (1993) employ a similar, yet somewhat different measure, in comparing estimation models for exchange rate volatility. Their measure reflects the amount, on an invested dollar, that the investor can save if his suboptimal utility level is obtained by investing an amount less than his current wealth in the 
optimal portfolio. ${ }^{5}$ Using the form of the CARA expected utility in equation (1), equation (7.a) takes the following form:

$$
-\exp \left\{-A\left(\mu_{p}^{*}-\theta\right)+(1 / 2) A^{2} \sigma_{p}^{*}\right\}=-\exp \left\{-A \hat{\mu}_{p}+(1 / 2) A^{2} \hat{\sigma}_{p}^{2}\right\}
$$

Solving for $\theta$ and utilizing equation (5) and (6) we have:

$$
\theta_{\mathrm{e}}=\left(\hat{\mu}_{\mathrm{p}}-\hat{\mu}_{\mathrm{p}}\right)+(1 / 2) \mathrm{A}\left(\hat{\sigma}_{\mathrm{p}}^{2}-\sigma_{\mathrm{p}}^{*}\right)
$$

Typically, $\left(\mu_{\mathrm{p}}-\hat{\mu}_{\mathrm{p}}\right)$ is positive and reflects the mean undershooting due to estimation errors. ${ }^{6}$ Moreover, $\left(\sigma_{p}^{2}-\sigma_{p}^{2}\right)$ is typically positive and reflects the risk overshooting due to estimation errors. ${ }^{7}$

According to (8), the opportunity cost of mean undershooting is independent of the measure of relative risk aversion A. However, the opportunity cost of risk overshooting increases with the measure of relative risk aversion. If $\Sigma$ is known, equation (5.a) and (6.a) imply a simplified form for $\theta_{\mathrm{e}}$ given as:

$$
\theta_{\mathrm{e}}=(1 / 2 \mathrm{~A})\left[\mathbf{b}-\mathrm{b}_{\mathrm{o}} \mathbf{e}\right]^{\prime} \Sigma^{-1}\left[\mathbf{b}-\mathrm{b}_{\mathrm{o}} \mathbf{e}\right]
$$

According to (9), the opportunity cost of the estimation error of a given portfolio depends on two factors: The measure of relative risk aversion, $\mathrm{A}$, and a metric that measures the severity of estimation risk, $\Phi_{b}=\left[\mathbf{b}-b_{0} \mathbf{e}\right]^{\prime} \Sigma^{-1}\left[\mathbf{b}-b_{0} \mathbf{e}\right]$. The latter is the Mahalanobis distance of the vector $\mathbf{b}$ from the vector $b_{o} \mathbf{e}$. Basically, it measures the variability of the estimation errors of individual markets around the estimation error of the GMVP, weighted by the covariance matrix. ${ }^{8}$ If the estimation errors are identical across markets,

5. ${ }^{5}$ The measure in West, Edison and Cho [1993] is the value of $*$ that satisfies the following equation:

$$
\mathrm{E}\left\{\mathrm{U}\left(\mathrm{w}_{0} \hat{\mathbf{X}} \cdot \tilde{\mathbf{R}}\right)\right\}=\mathrm{E}\left\{\mathrm{U}\left(\mathrm{w}_{0}[1-*] \mathbf{X} \cdot \tilde{\mathbf{R}}\right)\right\} .
$$

If we interpret both measures as fees to acquire the optimal strategy, then $\theta$ in (7.a) is the fee due to be paid from terminal wealth. Whereas $*$ is the fee due to be paid from current wealth now. It is the timing of the fee that makes thæ difference between the two measures.

${ }^{6}$ The reason is that $\mu_{\mathrm{p}}$ is the mean of the optimal portfolio while $\hat{\mu}_{\mathrm{p}}$ is its estimated value. The former is on the true mean variance efficient frontier while the latter is inside the frontier. While there is no guarantee that $\mu_{\mathrm{p}}>\mu_{\mathrm{p}}$ but it is often the case as our experience in the calculations indicate.

${ }^{7}$ The estimator of an efficient portfolio lies below the MVE frontier in the mean-variance plane. Still, its variance can be lower than efficient portfolio's variance. Moreover, its mean can be higher than the efficient portfolio's mean. Hence mean overshootng and variance undershooting cannot be ruled out. 8. ${ }^{8}$ Mahalanobis (1930) suggested this metric to measure the distance between the mean vectors of two joint normal distributions. This measure is invariant to any linear 
then $\Phi_{\mathrm{b}}=0$ and the opportunity cost of the estimation error is zero regardless of $\Sigma$ or A. If $\Sigma$ is positive definite, then a zero opportunity cost implies that estimation errors are identical across markets. However, when the estimation errors are not identical, the opportunity cost increases with the investor's risk tolerance. In the extreme when A $\rightarrow \infty, \mathbf{X}$ approaches the GMVP. Since the GMVP is independent of the mean vector, it is also independent of the estimation error vector $\mathbf{b}$. Hence: According to (8), the opportunity cost of $\mathbf{X}$ (A) approaches zero as $\mathrm{A} \rightarrow \infty$, regardless of the size of the estimation error.

\subsection{The cost of diversification versus the cost of country dedication:}

In the presence of estimation errors the full information optimal portfolio is not feasible. The investor's real choice is between two sub-optimal portfolios: a diversified portfolio based on false false parameters' specifications or the domestically dedicated one. The welfare loss of the former can outweigh the latter's for some investors, especially when the size of the estimation risk is very large. To see this let $\left(\mu_{i}, \sigma_{i}^{2}\right)$ be the mean variance pair of the return on market i and let $\left(\mu_{p}, \sigma_{p}^{2}\right)$ be the mean-variance pair of the full information optimal portfolio for the level of relative risk aversion A. According to equation (8), the opportunity cost of not diversifying is:

$$
\begin{aligned}
& \theta_{\mathrm{i}}=\left(\mu_{\mathrm{p}}-\mu_{\mathrm{i}}\right)+(1 / 2) \mathrm{A}\left(\sigma_{\mathrm{i}}^{2}-\sigma_{\mathrm{p}}^{2}\right) \\
& =\mu_{0}+(1 / \mathrm{A}) \mu \cdot \Sigma^{-1}\left[\boldsymbol{\mu}-\mu_{\mathrm{o}} \mathbf{e}\right]-\mu_{\mathrm{i}}+(1 / 2) \mathrm{A}\left[\sigma_{\mathrm{i}}^{2}-\left(\sigma_{0}^{2}+\left(1 / \mathrm{A}^{2}\right) \mu \cdot \Sigma^{-1}\left[\boldsymbol{\mu}-\mu_{\mathrm{o}} \mathbf{e}\right]\right)\right] \\
& =\mu_{0}+(1 / 2 \mathrm{~A}) \mu \Sigma^{-1}\left[\boldsymbol{\mu}-\mu_{\mathrm{o}} \mathbf{e}\right]-\mu_{\mathrm{i}}+(1 / 2) \mathrm{A}\left[\sigma_{\mathrm{i}}^{2}-\sigma_{0}^{2}\right] .
\end{aligned}
$$

For diversification to enhance the investor's welfare, the expected utility of his optimal portfolio, chosen under estimation risk, must exceed the expected utility of his home country dedicated portfolio. We explore the conditions under which this takes place in two stages: First, we assume that the covariance matrix is known and then we relax this assumption.

transformation of the joint normal variables. Rather than measuring the geometric distance, this metric weights the cross products of the differences between the two mean entries by the covariance matrix inverse. It coincides with the geometric distance when $\Sigma=\mathbf{I}$. 
If we let $\mathrm{h}_{\mathrm{i}}=\mathrm{A} \mu_{\mathrm{i}}-(1 / 2) \mathrm{A}^{2} \sigma_{\mathrm{i}}^{2}$ and $\mathrm{h}^{*}=\mathrm{A}_{*}^{*} \mu_{\mathrm{p}}-(1 / 2) \mathrm{A}^{2} \sigma_{\mathrm{p}}^{*}$, then diversification dominates country dedication if and only if $h_{i}<h^{*}$. Let $\Phi_{\mu}$ denote $\mu_{-1}^{\prime} \Sigma^{-1}\left[\mu-\mu_{0} \mathbf{e}\right]=$ $\left[\mu-\mu_{\mathrm{o}} \mathbf{e}\right]^{-\Sigma^{-1}}\left[\boldsymbol{\mu}-\mu_{\mathbf{o}} \mathbf{e}\right],^{\mathbf{9}}$ and recall that $\Phi_{\mathrm{b}}=\left[\mathbf{b}-\mathrm{b}_{\mathrm{o}} \mathbf{e}\right]^{-\Sigma^{-1}}\left[\mathbf{b}-\mathrm{b}_{\mathrm{o}} \mathbf{e}\right]$. Then equations (5.a) and (6.a) and the condition $\mathrm{h}_{\mathrm{i}}<\mathrm{h}^{*}$ implies,

$$
\left(\sigma_{i}^{2}-\sigma_{0}^{2}\right) A^{2}-2\left(\mu_{i}-\mu_{0}\right) A+\Phi_{\mu}-\Phi_{b}>0
$$

Since $\sigma_{0}{ }^{2}$ is the variance of the GMVP, $\left(\sigma_{i}^{2}-\sigma_{0}{ }^{2}\right)>0$. We have to distinguish among three cases:

Case (i): The quadratic function of $\mathrm{A}$ in the left hand side of (11.a) is positive for A>0. This implies that international diversification dominates domestic dedication for all investors, regardless of their risk preferences. It takes place under two conditions: (a) the quadratic term in (11.a) has no real roots, (b) the highest root of the quadratic is negative: The inequalities (12.a.1) and (12.a.2) reflect these conditions accordingly.

$$
\left(\mu_{\mathrm{i}}-\mu_{0}\right)^{2}-\left(\sigma_{\mathrm{i}}^{2}-\sigma_{0}^{2}\right)\left(\Phi_{\mu}-\Phi_{\mathrm{b}}\right)<0
$$

or

$$
\left[\left(\mu_{\mathrm{i}}-\mu_{0}\right)+\left[\left(\mu_{\mathrm{i}}-\mu_{0}\right)^{2}-\left(\sigma_{\mathrm{i}}^{2}-\sigma_{0}^{2}\right)\left(\Phi_{\mu}-\Phi_{\mathrm{b}}\right)\right]^{1 / 2}<0\right.
$$

Condition (12.a) takes place when $\Phi_{\mu}$ is very large relative to $\Phi_{b}$ or when $\sigma_{i}^{2}$ is very large relative to $\sigma_{0}{ }^{2}$. The former condition states that the cross-market variability in estimation errors is very small relative to the cross-market variability in the means. In such a case, diversification can be beneficial to all investors in all markets. In fact, when the domestic mean is equal to the mean of the GMVP, a variability in the means that exceeds the variability in estimation errors is enough to make international diversification dominate domestic dedication. Moreover, diversification dominates domestic dedication to investors for whom the variance of the home market is very large relative to the variance of the GMVP, or to investors for whom the home market mean is very weak relative to the mean of the GMVP. Both conditions imply that the domestic mean return is located far away from the mean variance efficient (MVE) frontier.

Case (ii): $\Phi_{\mathrm{b}}>\Phi_{\mu}$. In this case, one root of the quadratic in (11.a) is negative while the other is positive. The positive root is:

\footnotetext{
${ }^{9}$ The equality stems from the fact that $\mathbf{e}^{`} \Sigma^{-1}\left[\mu-\mu_{\mathrm{o}} \mathbf{e}\right]=0$.
} 
$\mathrm{A}_{1}=\left[\left(\mu_{\mathrm{i}}-\mu_{0}\right)+\left[\left(\mu_{\mathrm{i}}-\mu_{0}\right)^{2}+\left(\sigma_{\mathrm{i}}^{2}-\sigma_{0}^{2}\right)\left(\Phi_{\mathrm{b}}-\Phi_{\mu}\right)\right]^{1 / 2} /\left(\sigma_{\mathrm{i}}^{2}-\sigma_{0}^{2}\right)\right.$

Condition (11) holds for $A>A_{1}$. Only investors with a degree of relative risk aversion that exceeds the threshold $\mathrm{A}_{1}$ find international diversification preferred to domestic dedication.

Case (iii): $\Phi_{\mathrm{b}}<\Phi_{\mu}$ and neither (12.a.1) or (12.a.2) is satisfied. Under these conditions, there are two positive roots $A_{0}, A_{1}$ with $A_{0}<A_{1}$. Diversification here is beneficial for investors with a relative risk aversion parameter in the range $0<A<A_{0}$ or A> $A_{1}$.

\subsection{2 $\sum$ is not known:}

Let us introduce the following notations: $\hat{\Phi}_{\mu}=\left[\boldsymbol{\mu}-\hat{\mu}_{0} \mathbf{e}\right] \mathbf{S}^{-1}\left[\mu-\hat{\mu}_{0} \mathbf{e}\right]$, as the measure of the cross market variability of market means weighted by the inverse of the estimator of the covariance matrix,,$\hat{\Phi}_{\mathrm{b}}=\left[\mathbf{b}-\hat{\mathrm{b}}_{0} \mathbf{e}\right] \mathbf{S}^{-1}\left[\mathbf{b}-\hat{\mathrm{b}}_{0} \mathbf{e}\right]$, as a measure of the cross market variability in the estimation errors of market means, and $\Phi_{\mathrm{m}}=\left[\mathbf{m}-\mathrm{m}_{0} \mathbf{e}\right]^{\top}$ $\mathbf{S}^{-1}[\mathbf{S}-\Sigma] \mathbf{S}^{-1}\left[\mathbf{m}-\mathrm{m}_{0} \mathbf{e}\right]$. Note that $\Phi_{\mu}$ is different from $\hat{\Phi}_{\mu}$ in the following. The former measures the variability of market means around the mean of the GMV portfolio weighted by the inverse of the true covariance matrix, $\Sigma$. However, the latter measures the variability of market mean around the mean of the GMV portfolio estimator weighted by the inverse of the covariance matrix estimator. Moreover, $\Phi_{\mathrm{b}}$ and $\Phi_{\mathrm{b}}$ differ similarly. On the other hand, $\Phi_{\mathrm{m}}$ is zero if $\mathbf{S}=\Sigma$, non-negative if the bias matrix $\mathbf{S}-\Sigma$ is nonnegative, and non-positive if the bias matrix $\mathbf{S}-\boldsymbol{\Sigma}$ is non-positive. ${ }^{10}$ In appendix A, we show that international diversification dominates home country dedication if and only if the following condition takes place:

$$
\left(\sigma_{i}^{2}-\sigma_{0}^{2}\right) A^{2}-2\left(\mu_{i}-\hat{\mu}_{0}+\mathbf{a}_{0} \Sigma \Sigma \mathbf{S}^{-1}\left[\mathbf{m}-\mathrm{m}_{0} \mathbf{e}\right]\right) A+\hat{\Phi}_{\mathrm{m}}+\hat{\Phi}_{\mu}-\hat{\Phi}_{\mathrm{b}}>0
$$

Intuitively, we expect the zone of advantage for international diversification to be reduced here. This is because the additional estimation errors due to estimating the covariance matrix are likely to induce larger biases in the optimal portfolio weights and

\footnotetext{
${ }^{10} \mathbf{S}$ is positive definite. Therefore, its inverse is positive definite. In addition, the product of two positive definite matrices is also positive definite. Hence, $\mathbf{S}^{-\mathbf{1}}[\mathbf{S}-\Sigma] \mathbf{S}^{\mathbf{- 1}}$ is positive (negative) definite if and only if $[\mathbf{S}-\Sigma]$ is positive (negative) definite.
} 
lead to higher opportunity costs of mean-variance portfolios. On the other side, the opportunity cost of home country dedication is independent of the estimation errors. However, contrasting (11.a) with (11.b), shows that such a conclusion cannot be drawn regardless of $\Sigma$ and its estimator $\mathbf{S}$ for all risk aversion measures. Nonetheless, the fact that $\sigma_{0}^{2}>\sigma_{0}^{2}$ indicates that additional estimation errors in estimating the covariance matrix reduce the appeal of international diversification to investors with large measures of relative risk aversion. Still, condition (11.b) confirms the three main results of the previous case: (i) mean-variance international diversification may dominate country dedication, regardless of the measure of relative risk aversion; (ii) large cross market variability in the means favors mean-variance diversification; and (iii) large cross market variability in the estimation errors of these means favors country dedication. When $\mathbf{S}=\Sigma$ condition (11.a) is identical to condition (11.b).

\section{Empirical Demonstration}

Here we provide an empirical demonstration of the opportunity cost of estimation error. In doing so, we use monthly data equity returns on 11 countries over the period 1975-1994. These countries are: Australia, Austria, Belgium, Canada, France, Germany, Hong Kong, Japan, Spain, the UK and the US. Since the investor's home country can be an important factor in the diversification decision, the advantage of diversification is explored for investors living in three countries: Germany, Japan and the US. Evaluating the relative advantage of international diversification requires the knowledge of the true parameters of the joint distribution of the international market's returns as well as the best available way to estimate them. Since the knowledge of the true parameters is not feasible and since the best way to estimate them is a subject of controversy, we consider two methodologies:

In the first we assume that the distribution of market returns is stationary over time. We take the long run mean vector and the long run covariance matrix (over the period 1975-1995) as the true parameters of the stationary distribution. Here we assume that at the beginning of year $\mathrm{t}, \mathrm{t}=1980, \ldots, 1994$, the investor estimates the true distribution parameters using sample estimators over the 60 months preceding the beginning of year t. This makes the true distribution parameters depend on a long-run period that includes past and future data of the year under evaluation. International diversification is compared to home country dedication in two stages: first the covariance matrix is assumed to be known and then this assumption is relaxed by assuming that the covariance matrix is estimated using the same data from which mean vector is estimated. 
We do this to explore whether the additional covariance matrix estimation errors consistently lead to a narrower zone of advantage for international diversification.

The number of assets or countries are not relevant in affecting the variability in the estimation error, $\Phi_{\mathrm{b}}$. For example, if we have 2 stocks, 3 stocks or a 100 stocks and the estimation errors are identical, then $\Phi_{b}=0$ regardless of the size of the estimation errors. The number of countries, $N$, is irrelevant in this matter. One could have $\Phi_{b}=0$ with any number of countries and also could have a very large $\Phi_{b}$ with few countries. There is no clear direct relationship between $\mathrm{N}$ and $\Phi_{\mathrm{b}}$. Large sample size, however does matter. It results in lower estimation errors on average. At the extreme for a sample size $\mathrm{T}=\infty$ the estimation errors become zero and hence their variability becomes zero as well. However, between $T=60$ and $T=\infty$, the relationship between $T$ and $\Phi_{b}$ is not necessarily monotonic unless the speed of convergence of the estimated mean toward its true value is identical in all assets. Consistent with previous empirical literature, we use a 60 months window for the estimation.

In the second methodology we allow the mean return vector to change over time and take the true mean vector for a given year as the average monthly return over that year. Following Solnik (1993), we estimate these time varying means using information variables observable at the beginning of each year. This approach for modeling foreign market premia has been applied by Bekaert and Hodrick (1992), Campbell and Hamao (1992), Cutler, Poterba and Summers (1991) and Harvey (1991). The conditional variables that we use to predict the mean return in a given market are the following: the forward premium of that market, its dividend yield, and the term premium in that market defined as the difference between the 10-year government bond and the short term interest rate. $^{11}$

Certainly the above methods do not exhaust all possible ways to specify or estimate the distribution parameters. Still, they reflect two approaches commonly used in the literature and provide a robust test to the seriousness of the estimation errors in explaining the home equity bias puzzle. We are not aware of any alternative approach that dominates the above methodologies in specifying and estimating the distribution parameters. The presence of estimation errors often results in over-investment in markets

\footnotetext{
${ }^{11}$ The interest rate data on short-term interest rates are drawn from DataStream. The forward premium is calculated from the short-term interest rates using interest rate parity. In estimating the expected return of the domestic market (for Germany, Japan and the U.S) we use only two information variables: the dividend yield and the term premium. Since there is no long-term interest rate variable for Hong Kong in DataStream over the period 1975-1994, we are left with the forward premium and dividend yield to estimate the conditional mean for the Hong Kong market.
} 
with over-stated means and under-investment in markets with under-stated means. Investors can reduce their estimation risk exposure by imposing upper limits on their positions in foreign markets and ruling out short sales positions. ${ }^{12}$ We test the impact of such self-imposed constraints on reducing the opportunity cost of estimation errors.

\subsection{Stationary returns distribution:}

We provide elaborate analysis of the case in which the covariance matrix is known. Then we examine the sensitivity of the results by relaxing the assumption that the covariance matrix is known. Our main concern in the latter step is to test whether the additional errors in estimating the covariance matrix worsen the zone of advantage for international diversification and result in more home country bias.

\subsubsection{The covariance matrix is known:}

Table 1 reports some of the parameters that affect the decision to diversify internationally for investors living in Germany, Japan, and the US. For each home country we show the mean, $\mu_{\mathrm{o}}$, and the standard deviation, $\sigma_{0}$, of the (GMVP), the mean, $\mu_{i}$, and the standard deviation $\sigma_{i}$ of its market. Table 1 also reports $\mu\left(\sigma_{i}\right)$, the mean of the MVE portfolio that targets $\sigma_{i}$, and $\sigma\left(\mu_{i}\right)$ the standard deviation of the MVE portfolio that targets $\mu_{i}$. The former is the mean of the MVE portfolio positioned right above the home country dedicated portfolio and the latter is the standard deviation of the MVE portfolio positioned just to the left of the home country dedicated portfolio, in the $(\sigma, \mu)$ plane. The difference $\left[\mu\left(\sigma_{i}\right)-\mu_{i}\right]$ is the vertical distance of the domestic portfolio from the MVE frontier while $\left[\sigma_{i}-\sigma\left(\mu_{i}\right)\right]$ is the horizontal distance of the domestic portfolio from the MVE frontier. In addition, Table 1 reports $\Phi_{\mu}$, the metric that measures the mean variability across the 11 countries, and $\Phi_{b}$, the metric that measures the crossmarket variability in estimation errors.

Four facts emerge from the information presented in Table 1. First, the GMVP, $\left(\sigma_{0}, \mu_{0}\right)$, is different for investors living in different countries indicating that investors in Germany, Japan and the U.S face different MVE frontiers and hence different diversification opportunities. The U.S GMVP is not attainable by either the German or the Japanese investors and it dominates the lowest risk portfolio attainable by investors in either country. ${ }^{13}$ Second, the home country dedicated portfolio of the U.S investor is

\footnotetext{
12 See Jorion (1985), Frost and Savarino (1988), and Board and Sutcliffe (1992).

${ }^{13}$ It is clear that the U.S GMVP has both a higher mean and lower standard deviation than the German GMVP. U.S investors who tolerate the Japanese GMVP standard deviation of 0.050152 can attain an expected return that far exceeds the mean of the Japanese GMVP. This expected return is 0.017370. It can
} 
closer to its MVE frontier than in the cases for either the German or the Japanese investor. While the vertical distance of the U.S dedicated portfolio from the MVE frontier is 0.00479 , this vertical distance is 0.013716 for the German investor and 0.0107 for the Japanese investor. Similarly the horizontal distance of the U.S dedicated portfolio from the MVE frontier is 0.006185 , much lower than the horizontal distance of 0.040343 for the German investor and the horizontal distance 0f 0.032092 for the Japanese investor. Third, both $\Phi_{\mu}$ and $\Phi_{\mathrm{b}}$ are almost the same for investors living in any of the three countries. This is due to two facts: (i) The difference in the covariance matrix is the only source that drives the difference in either $\left(\boldsymbol{\mu}-\mu_{\mathrm{o}} \mathbf{e}\right)$ or $\left(\mathbf{b}-\mathrm{b}_{\mathrm{o}} \mathbf{e}\right)$ across home markets; ${ }^{14}$ (ii) the return covariance matrices of the three countries are not different enough to result in significant differences in these metrics. On the other hand, we have different values for cross-market variability in estimation error metrics in different years. This is because we have different estimators for the mean vector for each year during the 1980-94 period. Fourth, the variability in estimation errors exceeds the variability in the means over all 15 years under evaluation. Its average over this period is more than twice the value of the mean variability metric while it reached more than four times the value of the mean variability metric in 1989. This fact reduces the ability of the investor to benefit from international diversification regardless of his home country.

Since $\Phi_{\mathrm{b}}>\Phi_{\mu}$ in all years, the results of case (ii) in section 1.3.1 apply to international diversification in the period 1980-1994. This analysis implies that international diversification is preferred to home country investing for a subset of investors with a relative risk aversion measure that exceed a given threshold. Panel I of Table 2 provides the values of the threshold for the three countries over the fifteen-years

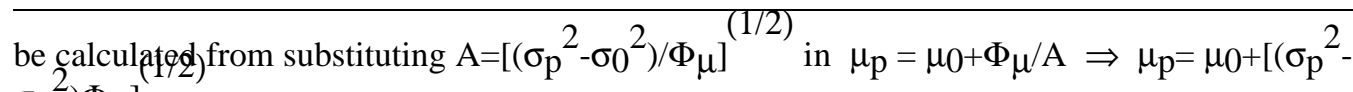
$\left.\left.\sigma_{0}^{2}\right) \Phi_{\mu}\right]$

${ }^{14}$ Let $\mathbf{R}^{\mathbf{U}}$ be the return vector of the 11 markets measured in U.S dollars, $\tilde{\mathbf{R}}^{\mathbf{J}}$ be the return vector measured in the Japanese Yen, and $\tilde{y}$ be the rate of dollar appreciation in terms of the Japanese Yen. In addition, let $\mu \mathbf{U}, \mu \mathbf{J}$, and $\mu_{y}$ be their respective means, and let $\Sigma \mathbf{U}, \Sigma \mathbf{J}$, and $\sigma_{\mathrm{y}}$ be their respective variances. By definition, $\tilde{\mathbf{R}} \mathbf{J}=\mathbf{R}^{\mathbf{U}}+\tilde{\mathrm{y}} \mathbf{e}$ and $\mu \mathbf{U}=$ $\mu^{\mathbf{J}}+\mu_{\mathrm{y}} \mathbf{e}$. Define the respective GMVP s as $\alpha_{0} \mathbf{U}$ and $\alpha_{0} \mathbf{J}$. Then,

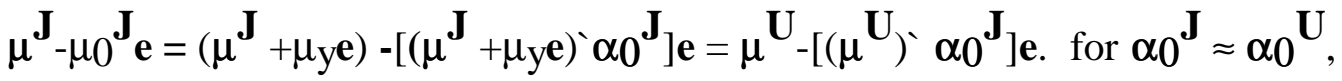

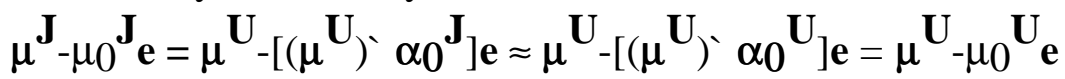

Note that the deviations of market means from the mean of the GMVP for the U.S investor only differ from those of his Japanese counter part due to the fact that their GMVP weights are different. However, the weights of the GMVP are solely determined by the covariance matrix. Thus, $\Sigma=\Sigma_{\mathbf{U}}^{\mathbf{U}} \Rightarrow \alpha_{\mathbf{J}} \mathbf{J}_{\mathbf{J}}$ $=\alpha_{0}{ }^{\mathbf{U}}, \quad \alpha_{0} \mathbf{J}=\alpha_{0} \Rightarrow \mu^{\mathbf{J}}-\mu_{0} \mathbf{J}=\mu_{-\mu_{0}}^{\mathbf{U}} \mathbf{e}$. The latter with $\Sigma=\Sigma$ imply $\Phi_{\mu}{ }^{\mathbf{U}}=\Phi_{\mu}$, it is not surprising to observe similar values of $\Phi_{\mu}$ ( or $\Phi_{b}$ ) across markets when the covariance matrix exhibit little change as a rusult of changing the currency in which returns are measured. 
evaluation period. It also provides the upper limit on the standard deviation (implied by the relative risk aversion threshold) for which international diversification is preferred to domestic dedication. It shows that the severity of the estimation errors induces home country bias on the behavior of a large set of investors on the lower end of risk aversion. Only U.S investors with extremely high levels of relative risk aversion find international diversification the superior strategy. The relative risk aversion measure has to exceed, on the average, 13.84 and the target standard deviation has to be on average lower than 0.0407. For the German investor, the relative risk aversion threshold is on the average 4.711 while the target standard deviation has to be on the average lower than 0.0783 . The Japanese investor thresholds are, on the average, 5.1559 and 0.0711 respectively.

This makes international diversification slightly less attractive to the Japanese investor than it is to the German investor. However, international diversification is far less attractive to both the Japanese and the German investors in comparison to the U.S investor. In addition, Table 2 reports the domestic market's standard deviation for the German, Japanese and U.S investors. If the markets' standard deviations reflect the risk tolerance of their representative investors, then the above thresholds indicate that the representative investors in the three countries exhibit home country bias. Panel I of Table 2 shows that the representative investor in Japan consistently exhibits home market dedication and that the representative investors in Germany and the U.S seldom do.

Table 3 consists of three sub-tables corresponding to Germany, Japan and the U.S.. Each sub-table provides the mean-standard-deviation pair of the optimal portfolios for three levels of relative risk aversion $(\mathrm{A}=7,4,1)$. In addition, it provides the true mean-standard-deviation pair of their estimators for the years 1980 through 1994, and the opportunity cost of these estimators as it is given in equation (8). It also provides the average values of the means, the standard deviations and the opportunity costs of the estimators of the full information optimal portfolios over the 15 years under evaluation. The last row provides the mean-standard- deviation pair and the opportunity cost of the home country dedicated portfolio. Notice that the table reports the true mean and the true standard deviation of estimators of the optimal portfolio and not their perceived values by the investor at the beginning of each year. The former is based on the true mean vector and the true covariance matrix, given by their long-run sample values. The latter is based on the mean vector estimated using a 60 month window, and the true covariance matrix.

Table 3 calls to our attention four points.

First, the standard deviation of the estimated portfolio overshoots the standard deviation of the optimal portfolio except in 1992, for the three countries and the three levels of relative risk aversion. The overshooting is worse the higher the investor's risk 
tolerance. The average overshooting is approximately $25 \%$ for investors with relative risk aversion $\mathrm{A}=7,44 \%$ for relative risk aversion $\mathrm{A}=4$, and $65 \%$ for relative risk aversion $\mathrm{A}=1$.

Second, the mean of the estimated portfolio undershoots the mean of the optimal portfolio in 11 of the 15 years under evaluation. However, the magnitude of mean undershooting is not as striking as the magnitude of the standard deviation overshooting.

Third, the opportunity cost of diversification for investors who should not diversify far exceeds the opportunity cost of foregoing diversification for investors who should diversify. To see this recall that according to Panel I of Table 2, German investors with a relative risk aversion $\mathrm{A}=4.711$ are, on the average, indifferent between international diversification and domestic dedication. Thus, investors with $\mathrm{A}=7$ should diversify while investors $A=1$ should not diversify. According to Table 3, the average opportunity cost of diversification for the German investor exceeds the opportunity cost of his domestic portfolio by 0.03913 for $A=1$. This excess amount can be seen as the opportunity cost of diversification when the investors should not diversify. Similarly, the opportunity cost of domestic dedication exceeds the opportunity cost of diversification by only 0.00446 for $A=7$. This indicates that making the wrong decision for $4.771<A<7$ is much more costly than making the wrong decision in the range $1<\mathrm{A}<4.771$. This conclusion applies also to investors in Japan and the U.S.

Fourth, while the results for the three countries are not identical, they are qualitatively similar. This holds for the magnitude of the opportunity cost of international diversification, and the size of overshooting (undershooting) the standard deviation (mean) of the full information optimal portfolio. On the other hand, the full information optimal portfolios of the high and medium levels of relative risk aversion are different, due to the different MVE sets faced by investors in the three countries. This difference, however, is much less for aggressive investors.

\subsubsection{The Covariance matrix is Unknown:}

Panel II of Table 2 provides the range of relative risk aversion values for which home country bias is inferior to international diversification using condition (11.b). It also provides the corresponding standard deviation range in the mean-standard-deviation. The term A $\varepsilon \Phi$ indicates that the zone of advantage for international diversification is the empty set. Recall that the GMV portfolio is independent of the mean vector and solely determined by the covariance matrix. Hence, when the covariance matrix is known the GMV portfolio is obtainable without any estimation error. Recall that the GMV portfolio 
is optimal for investors with $A=\infty$. It is not surprising, therefore, that when the covariance matrix is known, larger values of A result in optimal portfolios closer to the GMV portfolio and make international diversification more attractive. The presence of estimation errors in both the mean vector and the covariance matrix, contaminate the GMV portfolio with estimation errors, creating the theoretical possibility that international diversification can be inferior to home country dedication for $\mathrm{A}=\infty$.

Three major points emerge from the results in Panel II of Table 2. First, a larger number of estimation errors do not necessarily lead to a higher estimation risk. In some years, the zone of international diversification advantage is wider with estimation errors in both the mean vector and the covariance matrix. This takes place in the years 1980, 1983, and 1988 for Germany and Japan, and 1986 for the U.S. Second, investors with high degrees of risk tolerance (low measures of risk aversion) are less likely to opt for international diversification. The persistence of the latter result in this case confirms that it is not peculiar to the assumption of a known covariance matrix. Third, in most years and on average, estimating the covariance matrix leads to a narrower zone of advantage for international diversification. On average the opportunity cost of international diversification under estimation error in both the mean vector and the covariance is higher than the ones reported in Table $3 .^{15}$

\subsection{Mean returns are changing over time:}

If market mean returns exhibit trends, our measurement of estimation errors in the mean vector, in section 2.1, confounds trend movements with estimation errors. The investor might be able to reduce the estimation error in the mean vector by conditioning his estimation on economic variables known to him at the time he makes his allocation decision. The most commonly used variables are: the exchange rate forward premium, market dividend yields, and long and short term interest rates. We estimate the relationship between the return of a given market and its information variables. We do this by regressing the market return of month $t$ on the values of the information variables at the beginning of that month. The relationship for a given year is estimated using a 60 -month window preceding that year. Then the estimated regression parameters are used to project the expected return of the market. We follow Solnik [1993] in assuming that the true covariance matrix is its long run sample value. As the estimator of the covariance matrix

\footnotetext{
${ }^{15}$ To save space we do not report a table similar to TableIII. However, such a table is available from the authors.
} 
is taken as the sample covariance matrix based on a 60-month window preceding the year under evaluation.

Panel III of Table 2 provides the zone of advantage for international diversification both for the measure of relative risk aversion and the corresponding portfolio standard deviation. Note that in panel I and panel II the true market means are assumed to be equal to their long run sample means over the period 1975-1994. On the other hand, the true means of a given year, in panel III, are assumed to be the 12 month average of that year. This explains why the standard deviation thresholds for 1984 in Panel I and Panel III are very close $(7.41 \%$, and $7.21 \%$ respectively) whereas the respective relative risk aversion thresholds for the same year are far apart (4.65 and 12.09 respectively). This disparity is due to the fact that the 1984 non-stationary market means that the German investor faced at the beginning of 1984 , derived as the average over 1984, are radically different from the stationary means, derived as the long averages.

It seems that the conditional information approach does not provide better results than the stationary approach. Except 1982 for Germany, 1984 for Japan, and 1982 and 1985 for the U.S., using the conditional variables does not seem to enhance the zone of advantage for international diversification. This is due perhaps to the poor $\mathrm{R}^{2}$ of the regressions used to project the market means. ${ }^{16}$ With the poor $\mathrm{R}^{2}$ that we have, using the conditioning variables results in a much more severe estimation risk. Even if trends do exist, the problem of predicting these trends is hard enough to make the investor biased toward his home equity. Extending the analysis by incorporating time varying covariances based on the same set of conditioning variables will not improve our results. Time varying covariance model will increase the number of parameters beyond what we have in the time varying means case and hence reduce the degrees of freedom in the data. It seems that the mean varying model suffers from over parameterization problem. This problem is worsened with time varying covariances.

The fact that the threshold magnitudes are different in the three panels does not mean that zone of advantage on the mean variance efficient frontier for the three cases is much different. This is because as A gets large, the optimal portfolio approaches the global minimum variance portfolio. Therefore, investors with $A=10$ and $A=1000$ end up choosing practically the same portfolio, one that is hardly distinguishable from the global

\footnotetext{
${ }^{16}$ Recall that for Germany Japan and the U.S each we run 15 regressions on the conditional variables for the 15 years under evaluation. In these regressions $R^{2}$ varies from 0.01 to 0.35 . The variables are significant most the times. However, the small $\mathrm{R}^{2}$ reflects that there are large variations around the regression lines. This is likely to result in a large cross-market variability of estimation errors that dwarfs the cross-market variability of the true means.
} 
minimum variance portfolio. Thus the three models provide the same message. Only the extremely risk averse investors find international diversification advantageous.

\subsection{Self imposed short stales restrictions:}

Under the full information of the distribution parameters, short sales reduce the advantage of international diversification. After all, restricting the range of values that the decision variables are allowed to take will only reduce the highest attainable expected utility. However, short sales can result in diversified portfolios with lower estimation errors. Both the unrestricted estimator and the short sales restricted estimator of an optimal portfolio are sub-optimal. Moreover, the opportunity cost of the former may exceed that of the latter, especially for aggressive investors.

If short sales are ruled out, we can neither obtain a closed form solution for the optimal portfolio nor the mathematical relationships between the measure of relative risk aversion and the position of the optimal portfolio on the MVE set. Nor can we derive the relationship of the relative risk aversion to the opportunity cost of the estimation error given in equation (8). However, we obtain in section 1 a closed form for expected utility, $\mathrm{u}$. In addition, the monotone transformation of the expected utility $\mathrm{h}=-\ln (-\mathrm{u})$, given in (1.b), is a quadratic function in the portfolio allocation weights. Therefore, $\mathrm{h}$ can be maximized for different values of A using the quadratic programming algorithm in Markowitz (1987). This allows us to investigate the sensitivity of our analytical results to (i) estimation errors in both the covariance matrix and the mean vector and (ii) realistic restrictions on short sales. We obtain the restricted optimal portfolios by using the true mean vector and the true covariance matrix and by including the following short sales constraints in the quadratic program: (i) investors are not allowed to short any of the 11 markets and (ii) the position in any foreign market is not allowed to exceed 50\%. The restricted estimators of the optimal portfolios are calculated by including the short sales constraints in the quadratic program and using 60-month window estimators of both the mean vector and the covariance matrix. The restricted full information optimal portfolios and the estimators are calculated for the three levels of relative risk aversion $(\mathrm{A}=7,4,1)$ and for German, Japanese and U.S investors.

We compute the premium per invested dollar that a fully informed investor (an investor who knows the true mean vector and the true covariance matrix) is willing to pay to relax the short-sales constraints. This premium is the opportunity cost of the short-sales restricted full information optimal portfolio relative to the unrestricted full information optimal portfolio. We also calculate the short sales restricted estimators and their corresponding opportunity costs (relative to the unrestricted optimal portfolio). 
Consequently, the opportunity cost of an estimator consists of two components: The premium placed on relaxing the short sales constraints and the premium placed on obtaining the knowledge of both the true mean vector and the true covariance matrix.

Table 4 has a similar format to Table 3. It consists of three sub-tables corresponding to Germany, Japan and the U.S. The first row of each sub-table provides the mean standard deviation pair of the short sales restricted optimal portfolios as well as the opportunity cost of the short sales constraints. The table also provides the true mean standard deviation pair of the short-sales restricted estimators for the years 1980, ..., 1994, as well as their opportunity cost. The part of the opportunity cost that reflects the cost of full information is not reported. However, its value for a given estimator is the opportunity cost of the short sales restricted estimator minus the opportunity cost of the short sales constraints, given in the first row of the sub-table. In addition, each sub-table provides the average values for the mean, the standard deviation and the opportunity cost of the short sales restricted estimators over the 15 years under evaluation. Finally, the last row provides the mean standard deviation pair and the opportunity cost of the domestic portfolio.

According to Table 4, the opportunity costs of the short-sales constraints are small for the highly risk averse investors but they are extremely high for the aggressive investors, in the three countries. For $A=7$ its value is approximately 0.25 cents on an invested dollar, but it reaches ten times this amount for $A=1$. The short-sales restrictions force the fully informed investors with high risk aversion $(A=7)$ to choose optimal portfolios with a lower mean return and a higher standard deviation than otherwise. This is clear from the first row of the three sub-tables. However, as risk tolerance increases these investors are forced to choose portfolios with both lower means and lower standard deviations. This is because short sales constraints make a large part of the upper right side of the MVE frontier unattainable. For example, the short sales restrictions do not allow a fully informed German investor with $A=1$ to choose the unrestricted optimal portfolio that targets a mean of 0.07192 and a standard deviation of 0.25376 (first row of Table 3). Instead, the restrictions force him to choose the restricted optimal portfolio that targets a mean of 0.01974 and a standard deviation of 0.08039 . While the expected utility of the latter portfolio is lower (with an opportunity cost of 2.3 cents on an invested dollar), this is not the case when the opportunity costs of the respective estimators are compared. According to Table 3, the opportunity costs of the unrestricted estimators that a partially informed investor with $\mathrm{A}=1$ has to choose, range from 0.04382 to 0.14244 with an average of 0.07176. On the other hand, according to the German sub-table of Table 4, the short sales restrictions make such opportunity costs range from 0.02601 to 0.03461 with 
an average of 0.03003 . The latter figures are similar in magnitude for both Japan and the U.S.

It is clear from Table 3 and Table 4 that even when short sales are allowed, the partially informed investor can benefit from imposing such constraints. The estimators derived under the short sales constraints exhibit far lower opportunity costs than the unrestricted estimators for the three levels of risk aversion and the three countries. This is $\underline{\text { so in spite of the fact that the estimators in Table } 3 \text { are based on the true covariance matrix }}$ whereas the estimators in Table 4 are based on estimating both the mean vector and the covariance matrix. The improvement in the opportunity cost to highly aggressive investors is indeed significant. Unrestricted international diversification is much worse than domestic dedication for $\mathrm{A}=1$ in the three countries. However, short-sales constraints cause international diversification to be slightly preferred to domestic dedication for Germany and the U.S. Aggressive portfolios without short sales constraints, lead to extremely high means and extremely high standard deviations. Consequently, estimation errors make the partially informed investor choose a portfolio with more risk than he tolerates and a much lower mean than he expected. Table 3 confirms this observation for $A=1$. Short sales constraints eliminate this problem by ruling out portfolios with extreme risks and high means that are unrealistic for partially informed investors. Table 4, shows that the mean undershooting of investors with $A=1$ is much less than the unrestricted case while the standard deviation overshooting is also much smaller. Short sales constraints also help conservative investors. They cause international diversification to be slightly attractive for U.S investors with $A=4$ or 7 and enhance the advantage of international diversification for investors with $A=7$ in Japan and Germany.

\subsection{An equality test of market means:}

Our analysis shows that a high variability of the market-means' estimation errors that far exceeds the variability of the means themselves induces home country bias. When the market means are identical but their estimators are not, the former is positive and the latter is zero. Home country bias can be attributed here, at least in part, to a specification error of the probability distribution. With identical market means the efficient frontier becomes a single point in the mean-variance plane, the GMV portfolio. Hence equal means and a known covariance matrix make the GMV portfolio dominate any home country biased portfolio. ${ }^{17}$ When the covariance matrix is estimated, the variance of the

\footnotetext{
${ }^{17}$ Although the GMV portfolio is attainable to all investors when the market means are not identical, it does not dominate the home country dedicated portfolio for all preferences. Indeed, as Panel I of Table II show, aggressive investors prefer the home country dedicated portfolio located inside the MVE frontier
} 
estimated GMV portfolio may exceed the home country variance. In this instance, the investor prefers home country dedication over international diversification regardless of the measure of risk aversion. Panel II of Table 2 for which A $\varepsilon \Phi$ provides examples for such a case. ${ }^{18}$ Empirically, however, this takes place only once in fifteen years for Germany, and four times for the U.S. Therefore, identical market means are likely to make investors who do not commit specification error exhibit little home country bias.

Economic theory does not imply equal market means, even when Purchasing Power Parity (PPP) holds. For international capital markets to have identical means, at least the following two conditions must be satisfied: (i) PPP should hold and (ii) individual markets should have identical betas with respect to the world market portfolio [see Solnik (1974a)]. The restriction that market means are identical imposes a set of linear constraints on the mean vector. Seber (1984) provides a theory to test hypotheses that imply such restrictions on the mean vector of a joint normal distribution. The hypothesis that market means are identical can be formulated as follows:

$$
\mu_{\mathrm{i}}-\mu_{\mathrm{j}}=0 \quad \text { for } \mathrm{i}, \mathrm{j}=1, \ldots, \mathrm{d}
$$

According to Seber (1984), this is equivalent to the hypothesis that $\mathbf{C} \boldsymbol{\mu}=\mathbf{0}$ where $\mathbf{C}$ is a (d-1)xd restrtiction matrix of rank (d-1) satisfying the condition that $\mathbf{C} \mathbf{e}=\mathbf{0}$. For $\mathrm{d}=11$, equation 13 implies the following 10x11 restrictions matrix:

$\mathbf{C}=\begin{array}{rrrrrr}1 & -1 & 0 & \ldots & 0 & 0 \\ 0 & 1 & -1 & & 0 & 0 \\ . & . & . & & . & . \\ . & . & . & & . & . \\ . & . & . & & . & . \\ 0 & 0 & 0 & \ldots & 1 & -1\end{array}$

Under the null hypothesis the statistic $F=[n(n-d) /(n-1)(n-d)] \mathbf{m}^{\prime} \mathbf{C}^{\prime}\left(\mathbf{C S C}^{\prime}\right)^{-\mathbf{1}} \mathbf{C} \mathbf{m}$ follows a central $\mathrm{F}$ distribution with $(\mathrm{d}, \mathrm{n}-\mathrm{d})$ degrees of freedom. Using the entire data set makes $\mathrm{n}=240$. The following reports the test statistics for Germany, Japan and the U.S:

$\begin{array}{llll}\text { Country } & \text { Germany } & \text { Japan } & \text { U.S } \\ \text { F Statistic } & 65.0344 & 80.7367 & 56.8499\end{array}$

over the GMV located on the MVE frontier. However, when the market means are identical, the mean of the GMV portfolio is equal to the home country means. Yet, its variance is lower.

18 18. A $2 \varepsilon \Phi$ takes place when the left hand side of (11.b) is negative. For this to take place the condition $\sigma_{i}^{2}<\sigma_{0}^{2}$ (i.e. the variance, of the estimated GMV portfolio exceeds the home market variance) must hold. Theoretically, $\sigma_{i}{ }^{2}<\sigma_{0}$ can take place with a zone of international advantage bounded from below and from above. However, as Panel II of Table II indicates, this did not take place empirically. 
The $1 \%$ significance level critical $\mathrm{F}$ value is 2.3991 . The data provide a strong evidence for rejecting the hypothesis that investors in Germany, Japan and the U.S face identical market means. Breaking the data into five year windows and conducting the test provides similar results. ${ }^{19}$

\section{Summary and Conclusions}

Under full information, international diversification is optimal. However, under certain condition the cost of information is so great that there is a powerful inducement to deviate from the optimal choice of models that ignore its presence. Stiglitz (1961) provides this insight in a price search model where under certain conditions, the cost of information induces the localization of transactions. Here the lack of information induces country dedication under certain conditions. The foregone cost of this sub-optimal strategy depends on the distance of the home market from the MVE frontier, in the meanstandard-deviation plane. Clearly, the information that the investor can use is limited by the variables that he can observe and the sample on these variables. These informational constraints make the diversified alternative to the home-country dedicated portfolio impossible to attain. Instead, the best the investor can do is base his optimal portfolio on sample estimators contaminated by estimation errors that render all feasible portfolios suboptimal. The degree of contamination depends on the inter-market variability of estimation errors. On the other hand, the potential gain depends on the distance of the home market portfolio from the MVE frontier. The latter is home-country specific. However, both the former and the inter-market variability of estimation errors are identical for all investors, regardless of their home country.

Our analysis is valid regardless of whether the investment opportunity set constitutes international markets or a collection of domestic securities. Diversifying from a single stock to two or three stocks brings more gain than estimation risk cost. However, as the number of stocks increases, the marginal advantage of additional diversification can be outweighed by the cost of estimation risk. Thus the attractiveness of diversifying into international markets can be dominated by that cost. Our analysis shows that this is more likely to happen for investors with high-risk tolerance. The fact that each market by itself constitutes a diversified portfolio and the difficulty in estimating international markets' mean returns, make home dedication the preferred alternative. The potential gains from

\footnotetext{
${ }^{19}$ We conducted a similar test looking at four windows of five years each. The results show stronger evidence against the hypothesis that market means are identical to each other. The market means' sample estimators, the covariance matrix estimators, as well as the F statistics are available from the authors upon request.
} 
international diversification are not uniform to investors living in different home countries. For investors who live in large diversified economies, the gains from international diversification can be quickly outweighed by the negative impact of estimation errors, especially for investors who are not extremely risk averse. Whereas investors in small economies stand to gain more from international diversification, their institutional barriers to international investing are often more severe.

While our empirical analysis is restricted to a sample of 11 developed countries, the theoretical analysis here can shed some light on the effect of including emerging markets in the investment opportunity set. It is often argued that the fast growth in the emerging markets' economies provides a good reason to include them in high growth funds of investors living in developed countries. However, the short-term experience with these markets, as well as the political and the economic policy uncertainty associated with many of these markets, are likely to increase the opportunity cost of the estimation errors in the broader investment opportunity set that includes these markets. Our analysis indicates that diversifying with these markets is more likely to interest conservative investors in small economies than aggressive investors in large economies. 


\section{$\underline{\text { References }}$}

Bekaert, G. and Hodrick, R. (1992) Characterizing predictable components in excess returns on equity and foreign exchange markets. The Journal of Finance, 47, 467- 509.

Board, J. and Sutcliffe, C. (1994) Estimation methods in portfolio selection and the effectiveness of short sales restrictions: UK evidence. Management Science, 38, 516-534

Campbell, J.Y. and Hamao, Y. (1992) Predictable bond and stock returns in the United States and Japan: A study of long term capital market integration. Journal of Finance, 47, 30-70.

Cooper, I. and Kaplanis, E. (1994) Home bias in equity portfolio, inflation hedging, and international capital market equilibrium. The Review of Financial Studies, 7, 45-60.

Cutler, D. M., Poterba, J. and Summers, L.H. (1991) Speculative dynamics. Review of Economic Studies, 58, 529-546.

Dumas, B. and Solnik, B. (1995) The world price of foreign exchange rate risk. Journal of Finance, 50, 445-479.

French, K. and Poterba, J. (1991) Investor diversification and international equity markets. American Economic Review, 81, 222-226.

Ferson, W. E. and Harvey, C.R. (1993), The risk and predictabilty of international equity returns. Review of Financial Studies, 6, 527-566.

Frost A., and Savarino, J. (1983) For better performance: Constrain portfolio weights. Journal of Portfolio Management, 10, 315-334.

Grauer, R. and Hakansson, N.H. (1987) Gains from international diversification:1968-85 returns on portfolios of stocks and bonds. Journal of Finance, 42, 721-41.

Griffin, M.W. (1997) Why do pension and insurance portfolios hold so few international assets? Journal of Portfolio Management, 23, 45-50.

Harvey, C. R. (1991) The world price of covariance risk. The Journal of Finance, 45, 111-158.

Jorion, P. (1985) International diversification with estimation risk. Journal of Business, 58, 259-278.

Kang, J. and Stulz, R.M. (1996) Why is there a home bias? An analysis of foreign portfolio equity ownership in Japan" NBER Working paper \# 5166

Levy, H. and Larmen, Z. (1988) The benefits of international diversification of bonds. Financial Analyst Journal, September/October, 56-64.

Levy, H. and Sarnat, M. (1970) International diversification of investment portfolios. American Economic Review, 60, 668-675.

Markowitz, H. (1952) Portfolio selection. The Journal of Finance, 7, 77-91 
Markowitz, H. (1987) Mean-Variance Analysis in Portfolio Choice and Capital Markets, Basil Blackwell Publishers, New York.

Mohalanobis, P.C. (1930) On the generalized distance in statistics. Proc. Natl. Inst. Soc. India, 12, 49-55.

Mussa, M. and Goldstein, M. (1993) The integration of world capital markets. In Changing Capital Markets: Implications for Monetary Policy. Federal Reserve Bank of Kansas City, Kansas City, Missouri.

Odier, P. and Solnik. B. (1993) Lessons for international asset allocation. Financial Analyst Journal, March/April, 56-64.

Seber, G.A.F. (1984) Multivariate Observations, John Wiley and Sons, New York.

Simaan, Y. (1993) What is the opportunity cost of mean-variance investment strategies? Management Science, 39, 578-587.

Simaan, Y. (1997) Estimation risk in portfolio selection. The mean-variance model versus the mean absolute deviation model. 43, 126-148.

Solnik, B. (1974a) An equilibrium model for the international capital market. Journal of Economic Theory, 8, 500-524.

Solnik, B. (1974b) Why not to diversify internationally rather than domestically. Financial Analyst Journal, July/August, 3-22.

Solnik, B. (1993) The performance of international asset allocation strategies using conditioning infornation. The Journal of Empirical Finance, 1, 33-55.

Solnik, B. and Noetziln, B. (1982). Optimal international asset allocation. Journal of Portfolio Management, 9, 11-21.

Stigler, George J. (1961), The economics of information. Journal of Political Economy, LXIX (3), June, 48-59.

Tesar, L.L. and Werner, I.M. (1995) Home bias and high turnover. Journal of International Money and Finance, 14: 467-492.

Kenneth W.D., Edison, H.J. and Cho, D. (1993) A utility-base comparison of exchange rate volatility. Journal of International Economics, 35, 23-45. 


\section{Table 1}

\section{International Diversification Parameters}

\begin{tabular}{|c|c|c|c|}
\hline Country & Germany & Japan & U.S \\
\hline $\mathrm{u}_{\mathrm{n}}$ & ก กก71กก & 0011595 & $0 \cap 08515$ \\
\hline$\sigma_{n}$ & ก ก47617 & ก ก5015? & 0035347 \\
\hline $\begin{array}{l}\text { UI.i } \\
\| I .\left(\sigma_{i}\right)\end{array}$ & $\begin{array}{l}0 \Omega 17672 \\
0.026339\end{array}$ & $\begin{array}{l}\Omega \text { ONO697 } \\
0.031397\end{array}$ & $\begin{array}{l}\text { ח กח97ח } \\
0.013992\end{array}$ \\
\hline $\begin{array}{l}\sigma_{i} \\
\sigma\left(u_{i}\right)\end{array}$ & $\begin{array}{l}0 \cap 88412 \\
0.048070\end{array}$ & $\begin{array}{l}n \cap 04214 \\
0.062122\end{array}$ & $\begin{array}{l}\cap \cap 41624 \\
0.035449\end{array}$ \\
\hline$\Phi_{11}$ & 0.061687 & 0.061642 & 0.061926 \\
\hline$\Phi_{h}(1980)$ & 0.181409 & 0.181327 & 0.181707 \\
\hline$\Phi_{h}(1981)$ & 0.165015 & 0.164931 & 0.165437 \\
\hline$\Phi_{h}(1982)$ & 0.115964 & 0.115949 & 0.116463 \\
\hline$\Phi_{h}(1983)$ & 0.101635 & 0.101621 & 0.102095 \\
\hline$\Phi_{h}(1984)$ & 0.133636 & 0.133615 & 0.133958 \\
\hline$\Phi_{h}(1985)$ & 0.114579 & 0.114525 & 0.114538 \\
\hline$\Phi_{h}(1986)$ & 0.087686 & 0.087642 & 0.087778 \\
\hline$\Phi_{h}(1987)$ & 0.101528 & 0.101448 & 0.101050 \\
\hline$\Phi_{h}(1988)$ & 0.170136 & 0.170111 & 0.169733 \\
\hline$\Phi_{h}(1989)$ & 0.284886 & 0.284876 & 0.284126 \\
\hline$\Phi_{h}(1990)$ & 0.220892 & 0.220845 & 0.220295 \\
\hline$\Phi_{h}(1991)$ & 0.154177 & 0.154154 & 0.153940 \\
\hline$\Phi_{h}(1992)$ & 0.078748 & 0.078674 & 0.078531 \\
\hline$\Phi_{h}(1993)$ & 0.108231 & 0.108186 & 0.107753 \\
\hline$\Phi_{h}(1994)$ & 0.135045 & 0.135001 & 0.134639 \\
\hline Average $\left(\Phi_{h}\right)$ & 0.143571 & 0.143527 & 0.143470 \\
\hline
\end{tabular}

Investors' returns in each country are measured in terms of their home-country currency. For each year the mean return vector is estimated using monthly returns on country indices over the previous 5 year period. The true mean and the true covariance matrix of the country's market are assumed to be their long-run sample values over the period 19751994. $\mu_{0}$ and $\sigma_{0}$ are the mean and the standard deviation of the global minimum variance portfolio (GMVP) respectively. $\mu_{\mathrm{i}}$ and $\sigma_{\mathrm{i}}$ are the mean and the standard deviation of the market of country i. $\mu\left(\sigma_{i}\right)$ is the mean of the Mean-Variance Efficient (MVE) portfolio that targets $\sigma_{i}$ on the MVE set and $\sigma\left(\mu_{i}\right)$ is the standard deviations of the MVE portfolio that targets $\mu_{i}$ on the MVE set. $\Phi_{\mu}$ is a measure of the means variability across the 11 markets. $\Phi_{b}(t)$ is a measure of the estimation errors variability across the 11 markets. 
Table 2

The Zone of Diversification Advantage

\section{Germany}

Year
1980
1981
1982
1983
1984
1985
1986
1987
1988
1989
1990
1991
1992
1993
1994
Average

Long run $\sigma$

\section{Panel I}

Known covariance matrix and historical mean

\section{Panel II}

Estimated covariance matrix and historical mean estimators

$\begin{array}{lr}\text { A }>2.62 & \sigma<0.1039 \\ \text { A } \varepsilon \Phi & \\ \text { A }>157.30 & \sigma<0.0426 \\ \text { A }>19.23 & \sigma<0.0445 \\ \text { A }>3.37 & \sigma<\underline{0.0851} \\ \text { A }>49.86 & \sigma<0.0429 \\ \text { A }>7.54 & \sigma<0.0539 \\ \text { A }>4.10 & \sigma<0.0741 \\ \text { A }>14.65 & \sigma<0.0459 \\ \text { A }>3.10 & \sigma<\underline{0.0908} \\ \text { A }>14.75 & \sigma<0.0458 \\ \text { A }>11.66 & \sigma<0.0476 \\ \text { A }>17.14 & \sigma<0.0450 \\ \text { A }>26.57 & \sigma<0.0436 \\ \text { A }>24.93 & \sigma<0.0438 \\ \text { A }>25.49 & \sigma<0.0578 \\ & 0.0842\end{array}$

Estimated covariance matrix and historical mean estimators

$\begin{array}{lr}\text { A }>2.89 & \sigma<0.0995 \\ \text { A }>127.18 & \sigma<0.0502 \\ \text { A }>12.39 & \sigma<0.0540 \\ \text { A }>13.83 & \sigma<0.0533 \\ \text { A }>3.52 & \sigma<0.0865 \\ \text { A }>22.58 & \sigma<0.0513 \\ \text { A }>9.65 & \sigma<0.0564 \\ \text { A }>4.16 & \sigma<0.0780 \\ \text { A }>9.50 & \sigma<0.0566 \\ \text { A }>3.79 & \sigma<0.0825 \\ \text { A }>10.10 & \sigma<0.0558 \\ \text { A }>9.73 & \sigma<0.0563 \\ \text { A }>12.87 & \sigma<0.0537 \\ \text { A }>20.06 & \sigma<0.0517 \\ \text { A }>19.36 & \sigma<0.0518 \\ \text { A }>18.77 & \sigma<0.0625 \\ & 0.0942\end{array}$

\section{Panel III}

Estimated covariance matrix and conditional mean estimators

$\begin{array}{ll}\text { A } \varepsilon \Phi & \\ \text { A } \varepsilon \Phi & \\ \text { A }>51.02 & \sigma<0.0459 \\ \text { A }>301.82 & \sigma<0.0416 \\ \text { A }>12.09 & \sigma<0.0721 \\ \text { A }>275.77 & \sigma<0.0417 \\ \text { A }>79.20 & \sigma<0.0440 \\ \text { A }>41.49 & \sigma<0.0483 \\ \text { A }>58.15 & \sigma<0.0437 \\ \text { A }>32.10 & \sigma<0.0504 \\ \text { A }>77.87 & \sigma<0.0424 \\ \text { A }>121.75 & \sigma<0.0418 \\ \text { A }>115.84 & \sigma<0.0419 \\ \text { A }>122.65 & \sigma<0.0419 \\ \text { A > 62.84 } & \sigma<0.0423 \\ \text { A }>104.05 & \sigma<0.0460 \\ & 0.0842\end{array}$

\begin{tabular}{ccr} 
Japan & \multicolumn{3}{l}{ Known covariance matrix } \\
\multicolumn{3}{c}{ and historical mean } \\
Year & A $>6.00$ & $\sigma<0.0650$ \\
1980 & A $>5.71$ & $\sigma<0.0664$ \\
1981 & A $>4.68$ & $\sigma<0.0730$ \\
1982 & A $>4.32$ & $\sigma<0.0763$ \\
1983 & A $>5.09$ & $\sigma<0.0700$ \\
1984 & A $>4.65$ & $\sigma<0.0733$ \\
1985 & A $>3.91$ & $\sigma<0.0809$ \\
1986 & A $>4.31$ & $\sigma<0.0764$ \\
1987 & A $>5.80$ & $\sigma<0.0659$ \\
1988 & A $>7.53$ & $\sigma<0.0600$ \\
1989 & A $>6.63$ & $\sigma<0.0626$ \\
1990 & A $>5.50$ & $\sigma<0.0675$ \\
1991 & A $>3.60$ & $\sigma<0.0852$ \\
1992 & A $>4.49$ & $\sigma<0.0746$ \\
1993 & A $>5.12$ & $\sigma<0.0698$ \\
1994 & A $>5.16$ & $\sigma<0.0711$ \\
Average & & 0.0942
\end{tabular}

Estimated covariance matrix and conditional mean estimators

$\begin{array}{lrlr}\text { A }> & 18.3 & \sigma<0.0717 \\ \text { A } & 1539.1 & \sigma<0.041 \\ \text { A } & 37.49 & \sigma<0.049 \\ \text { A } & 215.96 & \sigma<0.0412 \\ \text { A } & 14.59 & \sigma<0.0639 \\ \text { A } & 20.43 & \sigma<0.0702 \\ \text { A } & 70.37 & \sigma<0.0443 \\ \text { A } & 66.10 & \sigma<0.0439 \\ \text { A } & 64.24 & \sigma<0.0429 \\ \text { A } & 17.69 & \sigma<0.0661 \\ \text { A } & 35.05 & \sigma<0.0455 \\ \text { A }>59.22 & \sigma<0.0424 \\ \text { A } & 50.67 & \sigma<0.0433 \\ \text { A } & 69.02 & \sigma<0.0424 \\ \text { A } & 76.38 & \sigma<0.0416 \\ \text { A }>156.98 & \sigma<0.0500 \\ & & & 0.0942\end{array}$




\section{U.S}

\begin{tabular}{ccc} 
& \multicolumn{2}{c}{ Known covariance matrix } \\
Year & and historical mean eestimators \\
1980 & A $>17.21$ & $\sigma<0.0382$ \\
1981 & A $>16.11$ & $\sigma<0.0386$ \\
1982 & A $>12.12$ & $\sigma<0.0409$ \\
1983 & A $>10.63$ & $\sigma<\underline{0.0424}$ \\
1984 & A $>13.70$ & $\sigma<0.0397$ \\
1985 & A $>11.94$ & $\sigma<0.0410$ \\
1986 & A $>8.86$ & $\sigma<\underline{0.0451}$ \\
1987 & A $>10.52$ & $\sigma<0.0425$ \\
1988 & A $>16.40$ & $\sigma<0.0385$ \\
1989 & A $>22.88$ & $\sigma<0.0370$ \\
1990 & A $>19.56$ & $\sigma<0.0376$ \\
1991 & A $>15.27$ & $\sigma<0.0389$ \\
1992 & A $>7.44$ & $\sigma<0.0487$ \\
1993 & A $>11.25$ & $\sigma<0.0417$ \\
1994 & A $>13.75$ & $\sigma<0.0397$ \\
Average & A $>13.84$ & $\sigma<0.0407$ \\
Long run $\sigma$ & & 0.0416
\end{tabular}

Estimated covariance matrix and historical mean estimators

$\begin{array}{ll}\text { A }>33.33 & \sigma<0.0361 \\ \text { A } \varepsilon \Phi & \end{array}$

A $\varepsilon \Phi$

A $\varepsilon \Phi$

A > $17.08 \quad 0.0382$

A $\varepsilon \Phi$

A $>14.22$

A $>4.39$

$\sigma<0.0394$

A $>64.49$

$\sigma<\underline{0.0668}$

A $>47.26$

$\sigma<0.0356$

A $>62.41$

A $>29.88$

A $>62.04$

A $>33.37$

A $>47.21$

A $>37.79$ $\sigma<0.0357$

$\sigma<0.0356$

$\sigma<0.0363$

$\sigma<0.0356$

$\sigma<0.0361$

$\sigma<0.0357$

$\sigma<0.0392$

0.0416
Estimated covariance matrix and conditional mean estimators

$\begin{array}{ll}\text { A }>789.68 & \sigma<0.0354 \\ \text { A } \varepsilon \Phi & \\ \text { A }>60.01 & \sigma<0.0391 \\ \text { A } \varepsilon \Phi & \\ \text { A }>130.15 & \sigma<0.0358 \\ \text { A }>23.902 & \sigma<\underline{0.0601} \\ \text { A }>47.076 & \sigma<\underline{0.0432} \\ \text { A }>56.599 & \sigma<0.0398 \\ \text { A }>75.365 & \sigma<0.0369 \\ \text { A }>287.73 & \sigma<0.0355 \\ \text { A }>162.05 & \sigma<0.0356 \\ \text { A }>284.54 & \sigma<0.0354 \\ \text { A }>395.05 & \sigma<0.0354 \\ \text { A }>53.622 & \sigma<0.0379 \\ \text { A }>340.37 & \sigma<0.0354 \\ \text { A }>208.17 & \sigma<0.0369 \\ & \end{array}$

Investors' returns in each country are measured in terms of their home currency. For each year the mean return vector is estimated using the monthly returns on country indices over the previous 5 year period. The table provides a range on the relative measure of risk aversion , A, in which international diversification dominates home country dedication. The range on $\sigma$, provides the range on the MVE set in the mean-standard-deviation plane implid by the range on the measure of relative risk aversion. the last row provides the long run standard deviation of the home market. Underlined figures signify a case for which the long-run $\sigma_{i}$ falls in the international diversification zone. 
Table 3

The Opportunity Cost of International Diversification When Short Sales are not Restricted

\begin{tabular}{cccccccccc}
\hline & $\mathrm{A}=7$ & \multicolumn{1}{c}{$\mathrm{A}=4$} & & & $\mathrm{~A}=1$ \\
\hline $\mathrm{E}$ & $\sigma$ & $\theta$ & $\mathrm{E}$ & $\sigma$ & $\theta$ & $\mathrm{E}$ & $\sigma$ & $\theta$
\end{tabular}

Germanv

Diversified True Optimal

$\begin{array}{lllllllll}0.01909 & 0.06332 & 0.00000 & 0.02569 & 0.08127 & 0.00000 & 0.07192 & 0.25376 & 0.00000\end{array}$

Estimated Optimal

Year

1980

1981

1982

1983

1984

1985

1986

1987

1988

1989

1990

1991

1992

1993

1994

Average

Country Dedicated

\begin{abstract}
$\begin{array}{lllllllll}0.02861 & 0.10214 & 0.01295 & 0.04236 & 0.16209 & 0.02267 & 0.13861 & 0.61570 & 0.09066\end{array}$ $\begin{array}{lllllllll}0.02711 & 0.09832 & 0.01178 & 0.03972 & 0.15469 & 0.02062 & 0.12805 & 0.58445 & 0.08247\end{array}$ $\begin{array}{lllllllll}0.02288 & 0.08638 & 0.00828 & 0.03234 & 0.13104 & 0.01449 & 0.09849 & 0.48320 & 0.05797\end{array}$ $\begin{array}{lllllllll}0.01979 & 0.07927 & 0.00726 & 0.02692 & 0.11648 & 0.01270 & 0.07682 & 0.41929 & 0.05081\end{array}$ $\begin{array}{lllllllll}0.01840 & 0.08086 & 0.00954 & 0.02448 & 0.11979 & 0.01670 & 0.06708 & 0.43395 & 0.06681\end{array}$ $\begin{array}{lllllllll}0.01886 & 0.07926 & 0.00818 & 0.02529 & 0.11645 & 0.01432 & 0.07032 & 0.41917 & 0.05726\end{array}$ $\begin{array}{llllllllll}0.01519 & 0.06844 & 0.00626 & 0.01887 & 0.09311 & 0.01096 & 0.04463 & 0.31215 & 0.04382\end{array}$ $\begin{array}{llllllllll}0.01498 & 0.07004 & 0.00725 & 0.01849 & 0.09667 & 0.01268 & 0.04313 & 0.32902 & 0.05072\end{array}$ $\begin{array}{lllllllll}0.01381 & 0.07728 & 0.01215 & 0.01645 & 0.11232 & 0.02126 & 0.03495 & 0.40071 & 0.08506\end{array}$ $\begin{array}{lllllllll}0.01320 & 0.09024 & 0.02035 & 0.01539 & 0.13878 & 0.03561 & 0.03073 & 0.51660 & 0.14244\end{array}$ $\begin{array}{llllllllll}0.01221 & 0.08094 & 0.01577 & 0.01365 & 0.11994 & 0.02761 & 0.02375 & 0.43461 & 0.11042\end{array}$ $\begin{array}{lllllllll}0.01155 & 0.07073 & 0.01101 & 0.01250 & 0.09820 & 0.01927 & 0.01916 & 0.33617 & 0.07708\end{array}$ $\begin{array}{lllllllll}0.01308 & 0.06244 & 0.00562 & 0.01518 & 0.07914 & 0.00983 & 0.02986 & 0.24277 & 0.03934\end{array}$ $\begin{array}{lllllllll}0.01561 & 0.07229 & 0.00773 & 0.01961 & 0.10162 & 0.01352 & 0.04760 & 0.35205 & 0.05409\end{array}$ $\begin{array}{lllllllll}0.01677 & 0.07812 & 0.00964 & 0.02164 & 0.11408 & 0.01688 & 0.05570 & 0.40860 & 0.06750\end{array}$ $\begin{array}{lllllllll}0.01747 & 0.07978 & 0.01025 & 0.02286 & 0.11696 & 0.01794 & 0.06059 & 0.41923 & 0.07176\end{array}$
\end{abstract}

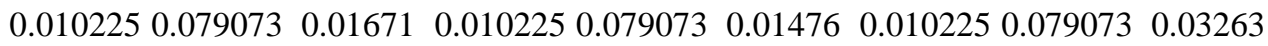

\title{
Japan
}

Diversified True Optimal

$\begin{array}{lllllllll}0.02040 & 0.06143 & 0.00000 & 0.02701 & 0.07980 & 0.00000 & 0.07324 & 0.25329 & 0.00000\end{array}$

Estimated Optimal
Year
1980
1981
1982
1983
1984
1985
1986
1987
1988
1989
1990
1991
1992
1993
1994

Average

Country Dedicated

\begin{abstract}
$\begin{array}{lllllllll}0.02993 & 0.10097 & 0.01295 & 0.04368 & 0.16136 & 0.02267 & 0.13992 & 0.61550 & 0.09066\end{array}$ $\begin{array}{lllllllll}0.02842 & 0.09711 & 0.01178 & 0.04104 & 0.15392 & 0.02062 & 0.12936 & 0.58425 & 0.08247\end{array}$ $\begin{array}{lllllllll}0.02420 & 0.08499 & 0.00828 & 0.03365 & 0.13014 & 0.01449 & 0.09981 & 0.48295 & 0.05797\end{array}$ $\begin{array}{lllllllll}0.02110 & 0.07776 & 0.00726 & 0.02823 & 0.11546 & 0.01270 & 0.07813 & 0.41900 & 0.05081\end{array}$ $\begin{array}{llllllllll}0.01971 & 0.07939 & 0.00954 & 0.02579 & 0.11880 & 0.01670 & 0.06839 & 0.43368 & 0.06681\end{array}$ $\begin{array}{llllllllll}0.02017 & 0.07775 & 0.00818 & 0.02660 & 0.11543 & 0.01432 & 0.07163 & 0.41889 & 0.05726\end{array}$ $\begin{array}{llllllllll}0.01650 & 0.06669 & 0.00626 & 0.02018 & 0.09183 & 0.01096 & 0.04594 & 0.31177 & 0.04382\end{array}$ $\begin{array}{llllllllll}0.01629 & 0.06832 & 0.00725 & 0.01981 & 0.09544 & 0.01268 & 0.04444 & 0.32866 & 0.05072\end{array}$ $\begin{array}{llllllllll}0.01512 & 0.07574 & 0.01215 & 0.01776 & 0.11126 & 0.02126 & 0.03627 & 0.40041 & 0.08506\end{array}$ $\begin{array}{llllllllll}0.01452 & 0.08891 & 0.02035 & 0.01671 & 0.13792 & 0.03561 & 0.03204 & 0.51637 & 0.14244\end{array}$ $\begin{array}{llllllllll}0.01352 & 0.07946 & 0.01577 & 0.01496 & 0.11895 & 0.02761 & 0.02506 & 0.43434 & 0.11042\end{array}$ $\begin{array}{lllllllll}0.01286 & 0.06903 & 0.01101 & 0.01381 & 0.09699 & 0.01927 & 0.02047 & 0.33582 & 0.07708\end{array}$ $\begin{array}{lllllllll}0.01439 & 0.06051 & 0.00562 & 0.01649 & 0.07763 & 0.00983 & 0.03117 & 0.24228 & 0.03934\end{array}$ $\begin{array}{lllllllll}0.01693 & 0.07063 & 0.00773 & 0.02093 & 0.10045 & 0.01352 & 0.04892 & 0.35172 & 0.05409\end{array}$ $\begin{array}{lllllllll}0.01808 & 0.07659 & 0.00964 & 0.02295 & 0.11304 & 0.01688 & 0.05702 & 0.40831 & 0.06750\end{array}$ $\begin{array}{lllllllll}0.01878 & 0.07826 & 0.01025 & 0.02417 & 0.11591 & 0.01794 & 0.06190 & 0.41893 & 0.07176\end{array}$
\end{abstract} $\begin{array}{lllllllll}0.01519 & 0.09421 & 0.02307 & 0.01519 & 0.09421 & 0.01683 & 0.01519 & 0.09421 & 0.03040\end{array}$ 


\section{U.S}

Diversified True Optimal

$\begin{array}{lllllllll}0.01736 & 0.05013 & 0.00000 & 0.02400 & 0.07155 & 0.00000 & 0.07044 & 0.25135 & 0.00000\end{array}$

Estimated Optimal

Year
1980
1981
1982
1983
1984
1985
1986
1987
1988
1989
1990
1991
1992
1993
1994

Average

$\begin{array}{lllllllll}0.02685 & 0.09455 & 0.01305 & 0.04065 & 0.15745 & 0.02275 & 0.13685 & 0.61445 & 0.09095 \\ 0.02535 & 0.09035 & 0.01185 & 0.03795 & 0.14975 & 0.02075 & 0.12615 & 0.58305 & 0.08275 \\ 0.02115 & 0.07725 & 0.00835 & 0.03055 & 0.12515 & 0.01465 & 0.09655 & 0.48145 & 0.05825 \\ 0.01805 & 0.06915 & 0.00735 & 0.02515 & 0.10985 & 0.01285 & 0.07485 & 0.41725 & 0.05105 \\ 0.01665 & 0.07095 & 0.00965 & 0.02275 & 0.11335 & 0.01675 & 0.06515 & 0.43185 & 0.06705 \\ 0.01715 & 0.06915 & 0.00825 & 0.02355 & 0.10985 & 0.01435 & 0.06865 & 0.41715 & 0.05735 \\ 0.01345 & 0.05645 & 0.00635 & 0.01715 & 0.08475 & 0.01105 & 0.04295 & 0.30975 & 0.04395 \\ 0.01325 & 0.05835 & 0.00725 & 0.01685 & 0.08855 & 0.01265 & 0.04165 & 0.32645 & 0.05055 \\ 0.01215 & 0.06685 & 0.01215 & 0.01475 & 0.10545 & 0.02125 & 0.03345 & 0.39865 & 0.08495 \\ 0.01155 & 0.08145 & 0.02035 & 0.01375 & 0.13325 & 0.03555 & 0.02935 & 0.51475 & 0.14215 \\ 0.01055 & 0.07105 & 0.01575 & 0.01195 & 0.11345 & 0.02755 & 0.02225 & 0.43235 & 0.11015 \\ 0.00985 & 0.05915 & 0.01105 & 0.01085 & 0.09025 & 0.01925 & 0.01765 & 0.33375 & 0.07705 \\ 0.01135 & 0.04895 & 0.00565 & 0.01355 & 0.06905 & 0.00985 & 0.02835 & 0.23955 & 0.03935 \\ 0.01395 & 0.06105 & 0.00775 & 0.01795 & 0.09395 & 0.01355 & 0.04615 & 0.34975 & 0.05395 \\ 0.01505 & 0.06785 & 0.00965 & 0.01995 & 0.10725 & 0.01685 & 0.05425 & 0.40655 & 0.06735 \\ 0.01575 & 0.06955 & 0.01025 & 0.02115 & 0.11005 & 0.01795 & 0.05895 & 0.41715 & 0.07175\end{array}$

Country Dedicated

Investors' returns are measured in terms of their home market. For each year the mean return vector is estimated using monthly returns over the previous 5 year period. The true mean and the true covariance matrix are assumed to be the long-run sample values over the period 1975-1994. For three levels of relative risk aversion, A, the optimal portfolio is calculated using the true values of the mean vector and the covariance matrix, assuming that short sales are allowed without restriction. In addition, using the annual estimators of the mean vector and the covariance matrix over the period 1980-1994, the estimator of the optimal portfolio is calculated for each of the three levels of risk aversion in each of the fifteen year. This table provides the mean, E, the standard deviation, $\sigma$, and the opportunity cost, $\theta$, of the estimators of each of the optimal portfolio as well as the opportunity cost of the home country dedicated portfolio for the German, the Japanese and the U.S markets. 
Table 4

\section{The Opportunity Cost of International Diversification When short Sales are Restricted}

\begin{tabular}{|c|c|c|c|c|c|c|c|c|c|}
\hline & \multicolumn{2}{|l|}{$A=7$} & & \multicolumn{3}{|c|}{$A=4$} & \multicolumn{3}{|c|}{$A=1$} \\
\hline & $\mathrm{E}$ & $\sigma$ & $\theta$ & $\mathrm{E}$ & $\sigma$ & $\theta$ & $\mathrm{E}$ & $\sigma$ & $\theta$ \\
\hline $\begin{array}{l}\text { Germanv } \\
\text { Diversified True }\end{array}$ & & & & & & & & & \\
\hline $\begin{array}{c}\text { Estimated Optima } \\
\text { Year }\end{array}$ & 0.01514 & 0.06060 & 0.00277 & 0.01576 & 0.06236 & 0.00450 & 0.01974 & 0.08039 & 0.02322 \\
\hline & 0.01290 & 0.06490 & 0.00690 & 0.01497 & 0.07601 & 0.00907 & 0.01692 & 0.08636 & 0.02654 \\
\hline 1981 & 01339 & 0.06467 & 0.00630 & 0.01541 & 0.07669 & 0.00883 & 0.01640 & 0.08247 & 0.02673 \\
\hline 19 & .01406 & 0.07358 & 0.00995 & 0.01527 & 0.07995 & 0.01000 & 0.01726 & 0.08411 & 0.02601 \\
\hline & .01211 & 0.06310 & 0.00688 & 0.01205 & 0.06839 & 0.00978 & 0.01314 & 0.07396 & 0.02932 \\
\hline & .01200 & 0.06339 & 0.00711 & 0.01080 & 0.06009 & 0.00890 & 0.00892 & 0.06608 & 0.03299 \\
\hline & .01175 & 0.06753 & 0.00927 & 0.01220 & 0.06866 & 0.00971 & 0.01220 & 0.06866 & 0.02989 \\
\hline & 01168 & 0.06526 & 0.00828 & 0.01236 & 0.07164 & 0.01039 & 0.01271 & 0.07930 & 0.03016 \\
\hline & .01123 & 0.06234 & 0.00742 & 0.01184 & 0.07190 & 0.01098 & 0.01239 & 0.08118 & 0.03063 \\
\hline & .01435 & 0.07743 & 0.01168 & 0.01348 & 0.07823 & 0.01125 & 0.00845 & 0.08166 & 0.03461 \\
\hline & .01472 & 0.08045 & 0.01298 & 0.01349 & 0.08000 & 0.01179 & 0.00845 & 0.08166 & 0.03461 \\
\hline & .01214 & 0.07199 & 0.01105 & 0.01205 & 0.07753 & 0.01245 & 0.01205 & 0.07753 & 0.03068 \\
\hline & .01092 & 0.06215 & 0.00766 & 0.01124 & 0.07084 & 0.01128 & 0.00843 & 0.07300 & 0.03397 \\
\hline & .00970 & 0.05645 & 0.00651 & 0.01067 & 0.05773 & 0.00848 & 0.01513 & 0.07924 & 0.02774 \\
\hline 1993 & 0.01430 & 0.0705 & 0.00817 & 0.01435 & 0.07080 & 0.00816 & 0.01438 & 0.07114 & 0.02788 \\
\hline 1994 & 0.01435 & 0.07080 & 0.00825 & 0.01432 & 0.07107 & 0.00826 & 0.01420 & 0.07927 & 0.02866 \\
\hline Average & 0.01264 & 0.06764 & 0.00856 & 0.01297 & 0.07197 & 0.00996 & 0.01274 & 0.07771 & 0.03003 \\
\hline Country Dedicated & 0.01023 & 0.07907 & 0.01671 & 0.01023 & 0.07907 & 0.01476 & 0.01023 & 0.07907 & 0.03263 \\
\hline
\end{tabular}

\section{Japan}

Diversified True Optimal

Estimated Optimal

Year
1980
1981
1982
1983
1984
1985
1986
1987
1988
1989
1990
1991
1992
1993
1994

$\begin{array}{lllllllll}0.01716 & 0.05916 & 0.00229 & 0.01880 & 0.06416 & 0.00370 & 0.02013 & 0.07001 & 0.02348\end{array}$

$\begin{array}{lllllllll}0.01265 & 0.06423 & 0.00899 & 0.01271 & 0.07413 & 0.01255 & 0.01692 & 0.08636 & 0.02797\end{array}$

$\begin{array}{lllllllll}0.01249 & 0.06338 & 0.00876 & 0.01281 & 0.07356 & 0.01228 & 0.01609 & 0.08243 & 0.02846\end{array}$

$\begin{array}{lllllllll}0.01220 & 0.06213 & 0.00850 & 0.01273 & 0.07425 & 0.01256 & 0.01710 & 0.08367 & 0.02755\end{array}$

$\begin{array}{lllllllll}0.01087 & 0.05960 & 0.00875 & 0.01265 & 0.05828 & 0.00841 & 0.01171 & 0.06940 & 0.03186\end{array}$

$\begin{array}{lllllllll}0.01087 & 0.06095 & 0.00933 & 0.01272 & 0.05791 & 0.00826 & 0.00845 & 0.06143 & 0.03460\end{array}$

$\begin{array}{lllllllll}0.01139 & 0.06484 & 0.01052 & 0.01288 & 0.06798 & 0.01063 & 0.01459 & 0.09436 & 0.03102\end{array}$

$\begin{array}{llllllllll}0.01031 & 0.06074 & 0.00980 & 0.01313 & 0.06359 & 0.00923 & 0.01271 & 0.07930 & 0.03159\end{array}$

$\begin{array}{lllllllll}0.00984 & 0.05705 & 0.00874 & 0.01299 & 0.06574 & 0.00992 & 0.01272 & 0.08218 & 0.03182\end{array}$

$\begin{array}{llllllllll}0.01380 & 0.07627 & 0.01375 & 0.01284 & 0.07944 & 0.01405 & 0.01519 & 0.09436 & 0.03042\end{array}$

$\begin{array}{llllllllll}0.01332 & 0.07706 & 0.01466 & 0.01283 & 0.07904 & 0.01393 & 0.01100 & 0.08472 & 0.03375\end{array}$

$\begin{array}{llllllllll}0.01119 & 0.06669 & 0.01157 & 0.01283 & 0.07255 & 0.01197 & 0.01205 & 0.07753 & 0.03211\end{array}$

$\begin{array}{lllllllll}0.00974 & 0.05752 & 0.00904 & 0.01283 & 0.06541 & 0.01000 & 0.00709 & 0.07253 & 0.03670\end{array}$

$\begin{array}{lllllllll}0.00909 & 0.05560 & 0.00893 & 0.01283 & 0.05735 & 0.00802 & 0.01466 & 0.07892 & 0.02961\end{array}$

$\begin{array}{lllllllll}0.01320 & 0.06512 & 0.00884 & 0.01283 & 0.06874 & 0.01089 & 0.01443 & 0.07197 & 0.02932\end{array}$

$\begin{array}{llllllllll}0.01335 & 0.06590 & 0.00905 & 0.01283 & 0.07171 & 0.01173 & 0.01420 & 0.07927 & 0.03010\end{array}$

Average

$\begin{array}{lllllllll}0.01162 & 0.06381 & 0.00982 & 0.01283 & 0.06865 & 0.01087 & 0.01326 & 0.07989 & 0.03109\end{array}$

Country Dedicated 


\section{U.S}

Diversified True Optimal

$\begin{array}{lllllllll}0.01256 & 0.04162 & 0.00207 & 0.01486 & 0.05126 & 0.00415 & 0.01721 & 0.06477 & 0.02374\end{array}$

Estimated Optimal

Year

1980

$\begin{array}{lllllllll}0.01427 & 0.05345 & 0.00429 & 0.01285 & 0.06452 & 0.00924 & 0.01678 & 0.07250 & 0.02470\end{array}$

$\begin{array}{lllllllllll}1981 & 0.01456 & 0.05323 & 0.00392 & 0.01283 & 0.06124 & 0.00843 & 0.01661 & 0.06411 & 0.02430\end{array}$

$\begin{array}{lllllllllll}1982 & 0.01444 & 0.05396 & 0.00431 & 0.01283 & 0.05559 & 0.00710 & 0.01717 & 0.06452 & 0.02377\end{array}$

$\begin{array}{lllllllllll}1983 & 0.01262 & 0.04620 & 0.00342 & 0.01283 & 0.04954 & 0.00583 & 0.01348 & 0.05129 & 0.02669\end{array}$

$\begin{array}{lllllllllll}1984 & 0.01088 & 0.03940 & 0.00312 & 0.01283 & 0.03987 & 0.00410 & 0.00871 & 0.05277 & 0.03154\end{array}$

$\begin{array}{llllllllll}1985 & 0.01181 & 0.04244 & 0.00306 & 0.01283 & 0.05908 & 0.00790 & 0.01206 & 0.04433 & 0.02777\end{array}$

$\begin{array}{llllllllll}1986 & 0.01158 & 0.04340 & 0.00358 & 0.01283 & 0.05302 & 0.00655 & 0.01257 & 0.05302 & 0.02769\end{array}$

$\begin{array}{llllllllll}1987 & 0.01148 & 0.04162 & 0.00315 & 0.01284 & 0.04882 & 0.00569 & 0.01288 & 0.05428 & 0.02745\end{array}$

$\begin{array}{llllllllll}1988 & 0.01238 & 0.05031 & 0.00505 & 0.01284 & 0.05163 & 0.00625 & 0.00832 & 0.05722 & 0.03217\end{array}$

$\begin{array}{llllllllll}1989 & 0.01207 & 0.05075 & 0.00552 & 0.01284 & 0.05249 & 0.00643 & 0.00832 & 0.05722 & 0.03217\end{array}$

$\begin{array}{llllllllll}1990 & 0.01187 & 0.04950 & 0.00527 & 0.01284 & 0.05163 & 0.00625 & 0.01186 & 0.05163 & 0.02833\end{array}$

$\begin{array}{llllllllll}1991 & 0.01050 & 0.03822 & 0.00318 & 0.01284 & 0.04181 & 0.00442 & 0.00900 & 0.04904 & 0.03106\end{array}$

$\begin{array}{llllllllll}1992 & 0.01001 & 0.03627 & 0.00317 & 0.01284 & 0.03804 & 0.00382 & 0.01404 & 0.05860 & 0.02653\end{array}$

$\begin{array}{lllllllllll}1993 & 0.01258 & 0.04804 & 0.00407 & 0.01284 & 0.05855 & 0.00778 & 0.01492 & 0.06307 & 0.02593\end{array}$

$1994 \quad \begin{array}{llllllllll}0.01383 & 0.05511 & 0.00537 & 0.01284 & 0.05826 & 0.00771 & 0.01407 & 0.06431 & 0.02685\end{array}$

Average

$\begin{array}{lllllllll}0.01233 & 0.04680 & 0.00403 & 0.01284 & 0.05227 & 0.00650 & 0.01272 & 0.05719 & 0.02780\end{array}$

\section{Country Dedicated}

$\begin{array}{lllllllll}0.00920 & 0.04163 & 0.00543 & 0.00920 & 0.04163 & 0.00802 & 0.00920 & 0.04163 & 0.03052\end{array}$

Investors' returns are measured in terms of their home market. For each year the mean return vector is estimated using monthly returns over the previous 5 year period. The true mean and the true covariance matrix are assumed to be the long-run sample values over the period 1975-1994. For three levels of relative risk aversion, A, the optimal portfolio is calculated using the true values of the mean vector and the covariance matrix, assuming that short sales are not allowed and the position in each foreign market can not exceed 0.5 . In addition, using the annual estimators of the mean vector and the covariance matrix over the period 1980-1994, the estimator of the optimal portfolio is calculated for each of the three levels of risk aversion in each of the fifteen year, assuming that short sales are not allowed and the position in each foreign market can not exceed 0.5 . This table provides the mean, E, the standard deviation, $\sigma$, and the opportunity cost, $\theta$, of the estimators of each of the optimal portfolio as well as the opportunity cost of the home country dedicated portfolio for the German, the Japanese and the U.S markets. 


\section{Appendix A}

Mean-variance diversification dominates home country dedication for investors living in country i if,

$$
\mathrm{h}_{\mathrm{i}}=\mathrm{A} \mu_{\mathrm{i}}-(1 / 2) \mathrm{A}^{2} \sigma_{\mathrm{i}}^{2}<\hat{\mathrm{u}}=\mathrm{A} \hat{\mu}_{\mathrm{p}}-(1 / 2) \mathrm{A}^{2} \sigma_{\mathrm{p}}^{2}
$$

Substituting the value of $\hat{\mu}_{p}$ according to (5.b) and the value of $\sigma_{p}^{2}$ according to (6.b),

$$
\begin{aligned}
\mathrm{A} \mu_{\mathrm{i}}-(1 / 2) \mathrm{A}^{2} \sigma_{\mathrm{i}}^{2}< & \mathrm{A} \hat{\mu}_{0}+\mu \mathbf{S}^{-1}\left[\mathbf{m}-\mathrm{m}_{0} \mathbf{e}\right]-(1 / 2) \mathrm{A}^{2}\left[\sigma_{0}^{2}+(2 / \mathrm{A}) \mathbf{a}_{0}{ }^{\prime} \Sigma \mathbf{S}^{-1}\left[\mathbf{m}-\mathrm{m}_{0} \mathbf{e}\right]\right. \\
& \left.+\left(1 / \mathrm{A}^{2}\right)\left[\mathbf{m}-\mathrm{m}_{0} \mathbf{e}\right] \mathbf{S}^{-1} \Sigma \mathbf{S}^{-1}\left[\mathbf{m}-\mathrm{m}_{0} \mathbf{e}\right]\right]
\end{aligned}
$$

This condition is equivalent to,

$$
\begin{gathered}
\left(\sigma_{i}^{2}-\sigma_{0}^{2}\right) A^{2}-2\left(\mu_{i}-\hat{\mu}_{0}+\mathbf{a}_{0}{ }^{\prime} \Sigma \mathbf{S}^{-1}\left[\mathbf{m}-\mathrm{m}_{0} \mathbf{e}\right]\right) \mathrm{A}+2 \mu \mathbf{S}^{-1}\left[\mathbf{m}-\mathrm{m}_{0} \mathbf{e}\right] \\
-\left[\mathbf{m}-\mathrm{m}_{0} \mathbf{e}\right] \mathbf{S}^{-1} \Sigma \mathbf{S}^{-1}\left[\mathbf{m}-\mathrm{m}_{0} \mathbf{e}\right]>0
\end{gathered}
$$

Using the fact that $\mathbf{m}=\boldsymbol{\mu}+\mathbf{b}, \mathrm{m}_{0}=\hat{\mu_{0}}+\hat{\mathrm{b}_{0}}$, the third term of (A.1) can be written as,

$$
\begin{aligned}
2 \mu \mathbf{S}^{-1}\left[\mathbf{m}-\mathrm{m}_{0} \mathbf{e}\right] & =2 \mu \cdot \mathbf{S}^{-1}\left[\left(\boldsymbol{\mu}-\hat{\mu}_{0} \mathbf{e}\right)+\left(\mathbf{b}-\hat{b}_{0} \mathbf{e}\right)\right] \\
& =2 \mu \mathbf{S}^{-1}\left[\boldsymbol{\mu}-\hat{\mu}_{0} \mathbf{e}\right]+2 \mu \mathbf{S}^{-1}\left[\mathbf{b}-\hat{b}_{0} \mathbf{e}\right]
\end{aligned}
$$

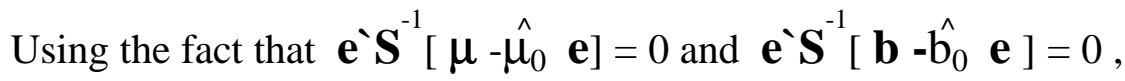

$$
\begin{aligned}
& 2 \mu \mathbf{S}^{-1}\left[\mathbf{m}-m_{0} \mathbf{e}\right]=2\left[\mu-\hat{\mu}_{0} \mathbf{e}\right] \mathbf{S}^{-1}\left[\boldsymbol{\mu}-\hat{\mu}_{0} \mathbf{e}\right]+2\left[\mu-\hat{\mu}_{0} \mathbf{e}\right] \mathbf{S}^{-1}\left[\mathbf{b}-\hat{b}_{0} \mathbf{e}\right]
\end{aligned}
$$

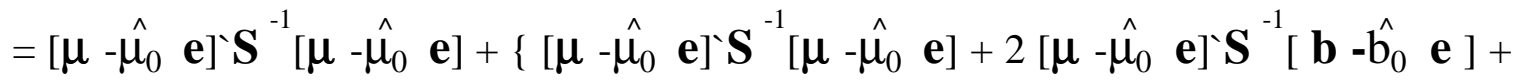

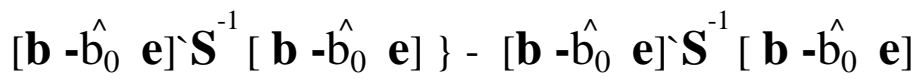

$$
\begin{aligned}
& =\left[\boldsymbol{\mu}-\hat{\mu}_{0} \mathbf{e}\right] \mathbf{S}^{-1}\left[\boldsymbol{\mu}-\hat{\mu}_{0} \mathbf{e}\right]+\left[\left(\boldsymbol{\mu}-\hat{\mu}_{0} \mathbf{e}\right)+\left(\mathbf{b}-\hat{b}_{0} \mathbf{e}\right)\right] \mathbf{S}^{-1}\left[\left(\boldsymbol{\mu}-\hat{\mu}_{0} \mathbf{e}\right)+\left(\mathbf{b}-\hat{b}_{0} \mathbf{e}\right)\right] \\
& -\left[\begin{array}{lll}
\mathbf{b} & -\hat{b}_{0} & \mathbf{e}
\end{array} \mathbf{S}^{-1}\left[\begin{array}{lll}
\mathbf{b} & -\hat{b}_{0} & \mathbf{e}
\end{array}\right]\right.
\end{aligned}
$$

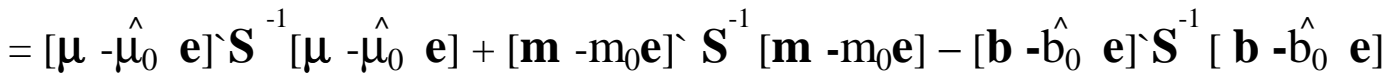

$$
\begin{aligned}
& =\hat{\Phi}_{\mu}+\hat{\Phi}_{\mathrm{m}}-\hat{\Phi}_{\mathrm{b}}
\end{aligned}
$$

Substituting the right hand side of the above equation for $2 \mu \mathbf{S}^{-1}\left[\mathbf{m}-\mathrm{m}_{0} \mathbf{e}\right]$ in (A.1) and collecting terms implies (11.b). 


\section{Endnotes}

1. Following French and Porteba (1991), we do not make any assumption regarding the purchasing power parity and moreover like most studies in portfolio analysis, we do not assume a risk free asset.

2. Mussa and Goldstein (1993) point to a host of transaction costs to cross-border investments extending from differences in language and information to official restrictions and policies that favor domestic asset trade. However, there is no easily interpreted measure of the economic importance of these transaction costs.

3. While French and Poterba (1991) state explicitly assumption (ii), assumption (i) is not mentioned. However, they use equation (1) as an implication of assumption (ii). But under (ii), equation (1) takes place if and only if the portfolio return is normally distributed. This is because assumption (i) implies that $\tilde{r_{p}} \sim \mathrm{N}\left(\mu_{\mathrm{p}}, \sigma_{\mathrm{p}}^{2}\right)$, with a moment generating function $\Phi_{r}(\mathrm{t})=\mathrm{E}\{\exp (\tilde{\operatorname{rap}})\}=\exp \left\{\mu_{\mathrm{p}} \mathrm{t}+(1 / 2) \mathrm{t}^{2} \sigma^{2} \mathrm{p}\right\}$. Assumption (ii) implies that $\mathrm{u}=$ $\Phi_{r}(-A)=-\exp \left\{-A \mu_{p}+(1 / 2) A^{2} \sigma_{p}^{2}\right\}=\exp \left\{-A X^{\prime} \mu+(1 / 2) A^{2} \mathbf{X}^{\prime} \Sigma \mathbf{X}\right\}$. Since the moment generating function uniquely determines the distribution of $\tilde{\mathrm{r}_{\mathrm{p}}}$, equation (1) implies the normality of $\tilde{\mathrm{r}_{\mathrm{p}}}$.

4. Recall that $b_{0}$ is a weighted average of the $b_{i}$. The weight of asset $i$ is equal to the $i^{\text {th }}$ entry of the global minimum variance portfolio, $\alpha_{0}$. If $b_{i}=b$ then $\mathbf{b}=b e$, and $b_{0}=\alpha_{0} ` e b=b$. Thus $\mathbf{b}-\mathbf{b}_{0} \mathbf{e}=\mathbf{0}$ and $\hat{\mathbf{X}}=\mathbf{X}^{*}$.

5. The measure in West, Edison and Cho [1993] is the value of $*$ that satisfies the following equation:

$$
\mathrm{E}\left\{\mathrm{U}\left(\mathrm{w}_{0} \hat{\mathbf{X}} \cdot \tilde{\mathbf{R}}\right)\right\}=\mathrm{E}\left\{\mathrm{U}\left(\mathrm{w}_{0}[1-*] \mathbf{X} \cdot \tilde{\mathbf{R}}\right)\right\} .
$$

If we interpret both measures as fees to acquire the optimal strategy, then $\theta$ in (7.a) is the fee due to be paid from terminal wealth. Whereas $*$ is the fee due to be paid from current wealth now. It is the timing of the fee that makes the difference between the two measures. 
6. The reason is that $\mu_{\mathrm{p}}$ is the mean of the optimal portfolio while $\hat{\mu_{\mathrm{p}}}$ is its estimated value. The former is on the true mean variance efficient frontier while the latter is inside the frontier. While there is no guarantee that $\mu_{\mathrm{p}}>\hat{\mu_{\mathrm{p}}}$ but it is often the case as our experience in the calculations indicate.

7. The estimator of an efficient portfolio lies below the MVE frontier in the meanvariance plane. Still, its variance can be lower than efficient portfolio's variance. Moreover, its mean can be higher than the efficient portfolio's mean. Hence mean overshootng and variance undershooting cannot be ruled out.

8. Mahalanobis (1930) suggested this metric to measure the distance between the mean vectors of two joint normal distributions. This measure is invariant to any linear transformation of the joint normal variables. Rather than measuring the geometric distance, this metric weights the cross products of the differences between the two mean entries by the covariance matrix inverse. It coincides with the geometric distance when $\Sigma=\mathbf{I}$.

9. The equality stems from the fact that $\mathbf{e}^{`} \Sigma^{-1}\left[\boldsymbol{\mu}-\mu_{\mathrm{O}} \mathbf{e}\right]=0$.

10. $\mathbf{S}$ is positive definite. Therefore, its inverse is positive definite. In addition, the product of two positive definite matrices is also positive definite. Hence, $\mathbf{S}^{\mathbf{- 1}}[\mathbf{S}-\Sigma] \mathbf{S}^{\mathbf{- 1}}$ is positive (negative) definite if and only if $[\mathbf{S}-\Sigma]$ is positive (negative) definite.

11. The interest rate data on short-term interest rates are drawn from DataStream. The forward premium is calculated from the short-term interest rates using interest rate parity. In estimating the expected return of the domestic market (for Germany, Japan and the U.S) we use only two information variables: the dividend yield and the term premium. Since there is no long-term interest rate variable for Hong Kong in DataStream over the period 1975-1994, we are left with the forward premium and dividend yield to estimate the conditional mean for the Hong Kong market. 
12. See Jorion (1985), Frost and Savarino (1988), and Board and Sutcliffe (1992).

13. It is clear that the U.S GMVP has both a higher mean and lower standard deviation than the German GMVP. U.S investors who tolerate the Japanese GMVP standard deviation of 0.050152 can attain an expected return that far exceeds the mean of the Japanese GMVP. This expected return is 0.017370 . It can be calculated from substituting $\mathrm{A}=\left[\left(\sigma_{\mathrm{p}}^{2}-\sigma_{0}^{2}\right) / \Phi_{\mu}\right]^{(1 / 2)}$ in $\mu_{\mathrm{p}}=\mu_{0}+\Phi_{\mu} / \mathrm{A} \Rightarrow \mu_{\mathrm{p}}=\mu_{0}+\left[\left(\sigma_{\mathrm{p}}{ }^{2}-\sigma_{0}{ }^{2}\right) \Phi_{\mu}\right]^{(1 / 2)}$.

14. Let $\mathbf{R}^{\mathbf{U}}$ be the return vector of the 11 markets measured in U.S dollars, $\tilde{\mathbf{R}}^{\mathbf{J}}$ be the return vector measured in the Japanese Yen, and $\tilde{y}$ be the rate of dollar appreciation in terms of the Japanese Yen. In addition, let $\mu \mathbf{U}, \mu \mathbf{J}$, and $\mu_{y}$ be their respective means, and let $\Sigma \mathbf{U}, \Sigma \mathbf{J}$, and $\sigma_{\mathrm{y}}$ be their respective variances. By definition, $\tilde{\mathbf{R}} \mathbf{J}=\mathbf{R}^{\mathbf{U}}+\tilde{\mathrm{y}} \mathbf{e}$ and $\mu \mathbf{U}=$ $\mu^{\mathbf{J}}+\mu_{\mathrm{y}} \mathbf{e}$. Define the respective GMVP s as $\alpha_{0} \mathbf{U}$ and $\alpha_{0} \mathbf{J}$. Then,

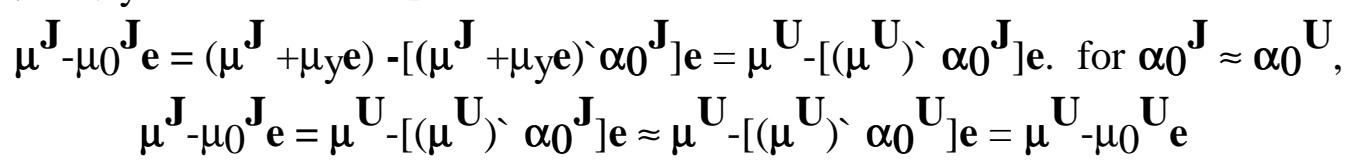
Note that the deviations of market means from the mean of the GMVP for the U.S investor only differ from those of his Japanese counter part due to the fact that their GMVP weights are different. However, the weights of the GMVP are solely determined by the covariance matrix. Thus, $\Sigma^{\mathbf{U}}=\Sigma^{\mathbf{J}} \Rightarrow \alpha_{0} \mathbf{J}=\alpha_{0} \mathbf{U}, \quad \alpha_{0} \mathbf{J}=\alpha_{0} \mathbf{U} \Rightarrow \mu_{-\mu_{0}}^{\mathbf{J}} \mathbf{e}=$ ${ }_{\mu} \mathbf{U}_{-\mu_{0}} \mathbf{U} \mathbf{e}$. The latter with ${ }_{\Sigma}^{\mathbf{U}}=\Sigma^{\mathbf{J}}$ imply $\Phi_{\mu}{ }^{\mathbf{U}}=\Phi_{\mu} \mathbf{J}$, it is not surprising to observe similar values of $\Phi_{\mu}$ ( or $\Phi_{\mathrm{b}}$ ) across markets when the covariance matrix exhibit little change as a rusult of changing the currency in which returns are measured.

15. To save space we do not report a table similar to TableIII. However, such a table is available from the authors.

16. Recall that for Germany Japan and the U.S each we run 15 regressions on the conditional variables for the 15 years under evaluation. In these regressions $\mathrm{R}^{2}$ varies from 0.01 to 0.35 . The variables are significant most the times. However, the small $\mathrm{R}^{2}$ reflects that there are large variations around the regression lines. This is likely to result in a large 
cross-market variability of estimation errors that dwarfs the cross-market variability of the true means.

17. Although the GMV portfolio is attainable to all investors when the market means are not identical, it does not dominate the home country dedicated portfolio for all preferences. Indeed, as Panel I of Table II show, aggressive investors prefer the home country dedicated portfolio located inside the MVE frontier over the GMV located on the MVE frontier. However, when the market means are identical, the mean of the GMV portfolio is equal to the home country means. Yet, its variance is lower.

18. A $\varepsilon \Phi$ takes place when the left hand side of (11.b) is negative. For this to take place the condition $\sigma_{i}^{2}<\sigma^{2}$ (i.e. the variance of the estimated GMV portfolio exceeds the home market variance) must hold. Theoretically, $\sigma_{i}^{2}<\sigma^{2} 0$ can take place with a zone of international advantage bounded from below and from above. However, as Panel II of Table II indicates, this did not take place empirically.

19. We conducted a similar test looking at four windows of five years each. The results show stronger evidence against the hypothesis that market means are identical to each other. The market means' sample estimators, the covariance matrix estimators, as well as the F statistics are available from the authors upon request. 